\title{
Padrão dos fluxos de capitais: teoria, evidência e puzzle *
}

\author{
Aderbal Oliveira Damasceno **
}

\section{Resumo}

Este trabalho desenvolve uma análise teórica e empírica sobre o padrão de longo prazo dos fluxos de capitais. Com uma amostra de 105 países e dados para o período 1980-2004, a metodologia econométrica abrange modelos para cross-section e para dados em painel. Os resultados apresentados sugerem: i) incoerência entre as previsões do modelo neoclássico e o padrão observado dos fluxos de capitais, o que caracteriza o puzzle; ii) no âmbito da abordagem convencional, as explicações para o puzzle são diferenças de fundamentos entre países e imperfeições no mercado financeiro; iii) não há evidências de que diferenças entre os países relativas ao ambiente institucional, estoque de capital humano, integração financeira, política macroeconômica e desenvolvimento financeiro expliquem o puzzle. Considerando os resultados apresentados, esboça-se uma explicação alternativa de inspiração heterodoxa para o padrão dos fluxos de capitais.

Palavras-chave: Integração financeira; Fluxos de capitais; Lucas Puzzle.

\section{Abstract \\ Pattern of capital flows: theory, evidence and puzzle}

This paper develops a theoretical and empirical analysis on the pattern of long-term capital flows. With a sample of 105 countries and data for the period 1980-2004, the econometric methodology includes models for cross-sectional and panel data. The results presented suggest: i) inconsistency between the predictions of the neoclassical model and the observed pattern of capital flows, which characterizes the puzzle; ii) under the conventional approach, the explanations for the puzzle are differences in fundamentals between countries and imperfections in financial markets; iii) there is no evidence that differences between countries regarding the institutional environment, human capital stock, financial integration, macroeconomic policy and financial development explain the puzzle. Considering the results presented, it outlines an alternative explanation of heterodox inspiration for the pattern of capital flows.

Keywords: Financial integration; Capital flows; Lucas Puzzle.

JEL F21, F41, F01.

\section{Introdução}

O aumento de eficiência na alocação internacional do capital é o argumento clássico em defesa da livre mobilidade de capitais. Nessa perspectiva, o capital deveria fluir dos países desenvolvidos, onde o capital seria relativamente abundante e o retorno marginal do capital seria baixo, para os países em

* Trabalho recebido em 21 de março de 2011 e aprovado em 12 de novembro de 2012.

* Professor do Instituto de Economia da Universidade Federal de Uberlândia (UFU), Uberlândia, MG, Brasil. E-mail: damasceno@ie.ufu.br. O autor agradece o auxílio financeiro fornecido pela Fundação de Amparo à Pesquisa do Estado de Minas Gerais (Fapemig). 
desenvolvimento, onde o capital seria relativamente escasso e o retorno marginal do capital seria alto, levando a uma alocação eficiente do capital em âmbito global. Lucas (1990) argumenta que a pequena magnitude observada dos fluxos de capitais direcionados aos países em desenvolvimento é incompatível com as previsões desse modelo, o que ficou conhecido na literatura como um puzzle, o Lucas Puzzle.

A literatura sobre o puzzle é relativamente ampla (Lucas, 1990; Gertler; Rogoff, 1990; Clemens; Williamson, 2004; Obstfeld; Taylor, 2004; Reinhart; Rogoff, 2004; Schularick, 2006; Caselli; Feyrer, 2007; Prasad et al., 2007; Eichengreen, 2007; Alfaro et al., 2008; Chirinko; Mallick, 2008; Acemoglu, 2009). No âmbito da abordagem convencional, as explicações para o puzzle podem ser agrupadas em duas amplas categorias: diferenças entre os países relativas aos fundamentos e imperfeições no mercado financeiro. Na literatura empírica, evidências sobre possíveis explicações para o puzzle são relativamente escassas, merecendo destaque aquelas apresentadas por Clemens e Williamson (2004) para o período 1870-1913 e por Alfaro et al. (2008) para o período 1970-2000.

O objetivo do trabalho é desenvolver uma análise teórica e empírica sobre o padrão de longo prazo dos fluxos de capitais. Com uma amostra de 105 países e dados para o período 1980-2004, a metodologia utilizada abrange análise de estatística descritiva, estimação de modelos para cross-section e para dados em painel. As evidências encontradas sugerem que: i) os capitais fluem pouco para os países em desenvolvimento e, no período recente, fluem em termos líquidos dos países em desenvolvimento para os países desenvolvidos; ii) diferenças entre os países relativas ao ambiente institucional, ambiente macroeconômico, integração financeira, estoque de capital humano e desenvolvimento financeiro não explicam porque os capitais fluem pouco para os países em desenvolvimento.

Essas evidências suscitam uma explicação de inspiração heterodoxa para o padrão dos fluxos de capitais fundamentada em três elementos: i) impossibilidade de mensurar a intensidade de capital de forma não ambígua e impossibilidade de estabelecer uma relação geral entre intensidade de capital e taxa de retorno do capital; ii) não ergodicidade do sistema econômico e teoria da preferência pela liquidez; iii) natureza centro-periferia do sistema monetário e financeiro internacional contemporâneo. Tendo por base esse arcabouço, não há elementos para prever que, em um ambiente de livre mobilidade de capitais, os capitais deveriam fluir, em termos líquidos, dos países desenvolvidos para os países em desenvolvimento e, portanto, o padrão observado dos fluxos de capitais não é um puzzle.

Este trabalho contribui para a literatura teórica e empírica sobre o padrão dos fluxos de capitais em três aspectos: i) sistematiza um amplo conjunto de informações sobre fluxos de capitais e estoques de obrigações para um amplo 
conjunto de países durante um longo período; ii) caracteriza o puzzle e, utilizando modelos para cross-section e para dados em painel, realiza uma ampla investigação econométrica sobre as possíveis explicações para o puzzle no âmbito da abordagem convencional; iii) esboça uma explicação alternativa de inspiração heterodoxa para o padrão dos fluxos de capitais. Por fim, a análise da direção e magnitude dos fluxos de capitais é particularmente relevante no contexto atual, já que está no epicentro do debate sobre desequilíbrio global e crise financeira global.

O trabalho está organizado em cinco seções além desta introdução: i) na seção 1, faz-se uma análise do padrão de integração financeira e dos fluxos de capitais; ii) na seção 2, documenta-se o puzzle no padrão dos fluxos de capitais; iii) na seção 3, apresentam-se explicações para o puzzle no âmbito da abordagem convencional e as evidências econométricas; iv) na seção 4, esboça-se uma explicação de inspiração heterodoxa para o padrão dos fluxos de capitais; v) na última seção são apresentadas as considerações finais.

\section{Integração financeira e fluxos de capitais: padrão global}

\subsection{Integração financeira}

O grau de mobilidade de capitais que caracteriza a atual configuração do sistema monetário e financeiro internacional é resultado de um conjunto de transformações que remonta à crise do arranjo institucional erigido em Bretton Woods, cujo marco é o colapso do sistema de paridades cambiais em 1973. Essas transformações têm origem na conversibilidade das moedas dos países europeus para transações em conta-corrente em 1958 e na constituição do euromercado ao longo da década de 60. É possível destacar três conjuntos de transformações subjacentes ao crescente grau de mobilidade dos fluxos de capitais:

Primeiro, e elemento central para explicação do crescente grau de mobilidade dos fluxos de capitais, as decisões de política econômica nos países centrais relativas à eliminação dos controles legais sobre os fluxos de capitais e à desregulamentação do sistema financeiro nas economias domésticas. Como destaca Prates (2002, p. 71), “[...] os determinantes principais do ambiente de livre mobilidade de capitais que emergiu após o colapso de Bretton Woods foram as decisões de política dos países centrais".

Segundo, os avanços tecnológicos, especialmente os progressos realizados nos setores de informática e de tecnologias de processamento de informações, que permitiram a redução dos custos de transação e a conexão entre as diversas praças financeiras. Como argumentam Eichengreen et al. (1998, p. 1), "Globalization has many dimensions [...] But nowhere does the revolution in information and communications technologies have such far-reaching ramifications as in the financial sphere." 
Terceiro, um conjunto de transformações financeiras, aprofundadas e consolidadas durante a década de 80 nos países desenvolvidos e ao longo da década de $90 \mathrm{com}$ a incorporação dos países em desenvolvimento, está subjacente ao crescente grau de mobilidade dos fluxos de capitais (Prates, 2002): i) a securitização das dívidas; ii) a institucionalização das poupanças; iii) a proliferação das inovações financeiras; e iv) a emergência dos investidores institucionais.

O Gráfico 1 mostra o comportamento do índice de integração financeira de jure CIIFI ao longo do período 1980-2004 para uma amostra total de 105 países, 22 países desenvolvidos e 83 países em desenvolvimento ${ }^{1}$. Há inequívoca tendência em direção a um maior nível de integração financeira em âmbito global: i) para a amostra total, o índice CIIFI aumenta de 38,62 em 1980 para 59,32 em 2004; ii) para a amostra de países desenvolvidos, o índice CIIFI aumenta de 53,64 em 1980 para 97,13 em 2004; iii) para a amostra de países em desenvolvimento, o índice CIIFI aumenta de 34,18 em 1980 para 49,17 em 2004.

Gráfico 1

Integração financeira: padrão global

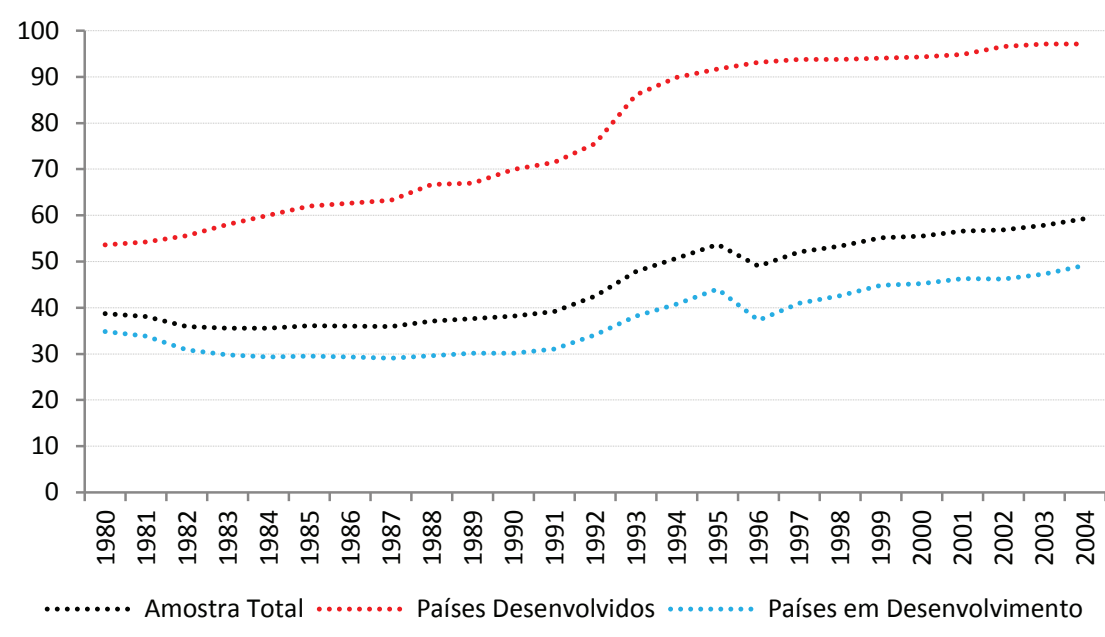

Fonte: Chinn e Ito (2008). Elaboração própria.

O padrão de comportamento do índice CIIFI permite três observações: i) há inequívoca tendência em direção a um maior nível de integração financeira em âmbito global; ii) até a década de 80 , o processo de integração financeira foi praticamente restrito aos países desenvolvidos; e iii) os países em desenvolvimento se integram, na década de 90, em menor intensidade.

(1) Todas as variáveis e amostras estão definidas, respectivamente, nos Quadros A1 e A2, em apêndice, e aparecem na ordem em que são apresentadas ao longo do texto. 


\subsection{Fluxos de capitais}

A Tabela 1 apresenta dados relativos a estoques de obrigações e fluxos de capitais durante o período 1980-2004 para uma amostra de 105 países, 22 países desenvolvidos e 83 países em desenvolvimento. Para a amostra total, o Estoque Total de Obrigações em 2004 é 16,15 vezes o valor de 1980 e o Fluxo Total de Capitais em 2004 é 9,65 vezes o valor de 1980. Para a amostra de países desenvolvidos, o Estoque Total de Obrigações em 2004 é 18,71 vezes o valor de 1980, o Estoque Total de Obrigações per capita em 2004 é 16,10 vezes o valor de 1980, o Fluxo Total de Capitais em 2004 é 10,07 vezes o valor de 1980 e o Fluxo Total de Capitais per capita em 2004 é 8,67 vezes o valor de 1980. Para a amostra de países em desenvolvimento, o Estoque Total de Obrigações em 2004 é 7,91 vezes o valor de 1980, o Estoque Total de Obrigações per capita em 2004 é 5,15 vezes o valor de 1980, o Fluxo Total de Capitais em 2004 é 6,70 vezes o valor de 1980 e o Fluxo Total de Capitais per capita em 2004 é 4,38 vezes o valor de 1980.

Os dados explicitam a assimetria do sistema financeiro internacional: i) em 1980 e 2004, o Estoque Total de Obrigações dos países desenvolvidos correspondia, respectivamente, a 3,21 vezes e 7,60 vezes o Estoque Total de Obrigações dos países em desenvolvimento; ii) em 1980 e 2004, o Fluxo Total de Capitais para os países desenvolvidos correspondia, respectivamente, a 7 vezes e 10,52 vezes o Fluxo Total de Capitais para os países em desenvolvimento. Essa assimetria é mais evidente para fluxos de capitais e estoques de obrigações per capita: i) em 1980 e 2004, o Estoque Total de Obrigações per capita dos países desenvolvidos correspondia, respectivamente, a 13,18 vezes e 41,22 vezes o Estoque de Obrigações per capita dos países em desenvolvimento; ii) em 1980 e 2004, o Fluxo Total de Capitais per capita para os países desenvolvidos correspondia, respectivamente, a 28,46 vezes e 56,37 vezes o Fluxo Total de Capitais per capita para os países em desenvolvimento.

Cabe destacar a modificação na composição de fluxos de capitais e estoques de obrigações ao longo do período, especialmente para os países em desenvolvimento. A participação de Estoque de Obrigações Equity no Estoque Total de Obrigações aumenta de 20\% em 1980 para 36\% em 2004 na amostra total, de $21 \%$ em 1980 para $34 \%$ em 2004 na amostra de países desenvolvidos, de $16 \%$ em 1980 para $51 \%$ em 2004 na amostra de países em desenvolvimento. A participação do Fluxo de Capitais Equity no Fluxo Total de Capitais aumenta de 14\% em 1980 para 18\% em 2004 na amostra total, mantém-se inalterada em 14\% na amostra de países desenvolvidos entre os anos 1980 e 2004 e aumenta de $10 \%$ em 1980 para $57 \%$ em 2004 na amostra de países em desenvolvimento. 
Tabela 1

Fluxo de capitais e estoque de obrigações - Padrão global

\begin{tabular}{|c|c|c|c|c|c|c|c|}
\hline & 1980 & $\begin{array}{c}1980- \\
1984\end{array}$ & $\begin{array}{c}1985- \\
1989 \\
\end{array}$ & $\begin{array}{c}1990- \\
1994 \\
\end{array}$ & $\begin{array}{c}1995- \\
1999 \\
\end{array}$ & $\begin{array}{c}2000- \\
2004 \\
\end{array}$ & 2004 \\
\hline \multicolumn{8}{|l|}{ Amostra Total } \\
\hline Estoque Total de Obrigações (US\$ Bilhões) & 3340,66 & 4059,46 & 8369,37 & 14789,78 & 25534,96 & 40793,56 & 53937,82 \\
\hline Estoque de Obrigações Debt (US\$ Bilhões) & 2675,52 & 3285,83 & 6524,59 & 11047,81 & 16447,13 & 25454,78 & 34359,07 \\
\hline Estoque de Obrigações Equity (US\$ Bilhões) & 665,13 & 773,62 & 1844,78 & 3736,79 & 8986,06 & 15017,73 & 19117,45 \\
\hline Fluxo Total de Capitais (US\$ Bilhões) & 487,90 & 396,13 & 741,41 & 978,17 & 2200,75 & 3425,22 & 4709,37 \\
\hline Fluxo de Capitais Debt (US\$ Bilhões) & 420,51 & 329,23 & 581,15 & 672,80 & 1304,59 & 2269,17 & 3884,86 \\
\hline Fluxo de Capitais Equity (US\$ Bilhões) & 67,39 & 66,90 & 160,26 & 305,38 & 894,62 & 1156,60 & 824,51 \\
\hline \multicolumn{8}{|l|}{ Países Desenvolvidos } \\
\hline Estoque Total de Obrigações (US\$ Bilhões) & 2547,53 & 3020,21 & 6727,78 & 12107,48 & 21256,40 & 35485,42 & 47666,15 \\
\hline Estoque de Obrigações Debt (US\$ Bilhões) & 2013,07 & 2408,41 & 5150,28 & 9031,71 & 13691,16 & 22674,85 & 31295,05 \\
\hline Estoque de Obrigações Equity (US\$ Bilhões) & 534,46 & 611,80 & 1577,50 & 3070,59 & 7463,66 & 12508,24 & 15930,58 \\
\hline Estoque Total de Obrigações per capita (US\$) & 3387,90 & 3966,61 & 8589,62 & 14955,47 & 25406,10 & 41080,55 & 54556,40 \\
\hline Estoque de Obrigações Debt per capita (US\$) & 2677,14 & 3163,13 & 6576,23 & 11158,11 & 16374,98 & 26241,40 & 35818,82 \\
\hline Estoque de Obrigações Equity per capita (US\$) & 710,76 & 803,47 & 2013,39 & 3791,04 & 8909,94 & 14489,54 & 18233,38 \\
\hline Fluxo Total de Capitais (US\$ Bilhões) & 426,92 & 335,18 & 724,28 & 836,03 & 1983,50 & 3195,67 & 4300,90 \\
\hline Fluxo de Capitais Debt (US\$ Bilhões) & 365,40 & 284,94 & 581,70 & 602,78 & 1274,57 & 2254,83 & 3710,52 \\
\hline Fluxo de Capitais Equity (US\$ Bilhões) & 61,51 & 50,24 & 142,58 & 233,25 & 707,22 & 940,84 & 590,37 \\
\hline Fluxo Total de Capitais per capita (US\$) & 567,75 & 441,14 & 924,67 & 1033,52 & 2369,70 & 3704,48 & 4922,61 \\
\hline Fluxo de Capitais Debt per capita (US\$) & 485,94 & 375,03 & 742,89 & 745,67 & 1524,99 & 2608,75 & 4246,89 \\
\hline Fluxo de Capitais Equity per capita (US\$) & 81,80 & 66,11 & 181,78 & 287,84 & 842,64 & 1095,73 & 675,71 \\
\hline \multicolumn{8}{|l|}{ Países em Desenvolvimento } \\
\hline Estoque Total de Obrigações (US\$ Bilhões) & 793,13 & 1039,25 & 1641,59 & 2682,30 & 4278,56 & 5308,14 & 6271,67 \\
\hline Estoque de Obrigações Debt (US\$ Bilhões) & 662,45 & 877,42 & 1374,31 & 2016,10 & 2755,97 & 2779,94 & 3064,03 \\
\hline Estoque de Obrigações Equity (US\$ Bilhões) & 130,68 & 161,82 & 267,29 & 666,20 & 1522,40 & 2509,49 & 3186,87 \\
\hline Estoque Total de Obrigações per capita (US\$) & 256,97 & 321,76 & 458,83 & 680,49 & 998,95 & 1149,74 & 1323,44 \\
\hline Estoque de Obrigações Debt per capita (US\$) & 214,63 & 271,62 & 384,24 & 512,21 & 644,34 & 602,61 & 646,57 \\
\hline Estoque de Obrigações Equity per capita (US\$) & 42,34 & 50,13 & 74,60 & 168,28 & 354,56 & 543,08 & 672,49 \\
\hline Fluxo Total de Capitais (US\$ Bilhões) & 60,98 & 60,96 & 17,13 & 142,14 & 217,25 & 229,55 & 408,48 \\
\hline Fluxo de Capitais Debt (US\$ Bilhões) & 55,11 & 44,29 & $-0,56$ & 70,01 & 30,02 & 14,34 & 174,34 \\
\hline Fluxo de Capitais Equity (US\$ Bilhões) & 5,87 & 16,66 & 17,69 & 72,13 & 187,40 & 215,77 & 234,14 \\
\hline Fluxo Total de Capitais per capita (US\$) & 19,95 & 19,34 & 4,86 & 36,22 & 51,69 & 50,22 & 87,32 \\
\hline Fluxo de Capitais Debt per capita (US\$) & 18,03 & 14,13 & $-0,11$ & 17,86 & 7,64 & 2,85 & 37,27 \\
\hline Fluxo de Capitais Equity per capita (US\$) & 1,92 & 5,21 & 4,97 & 18,36 & 44,08 & 47,50 & 50,05 \\
\hline
\end{tabular}

Nota: Elaboração própria com base nas informações divulgadas por Lane e Milesi-Ferretti (2007), International Financial Statistics (2008) e World Development Indicators (2007). Os dados para os períodos 1980-1984, 1985-1989, 1990-1994, 1995-1999 e 2000-2004 são médias anuais.

O padrão de comportamento das séries relativas a fluxos de capitais e estoques de obrigações permite três observações: i) o crescimento de fluxos de capitais e estoques de obrigações em âmbito global; ii) o crescimento da participação de equity na composição dos fluxos de capitais e estoques de obrigações; e iii) o caráter assimétrico do sistema financeiro internacional. 


\section{Puzzle no padrão dos fluxos de capitais}

\subsection{A teoria}

Sob os pressupostos de países produzindo os mesmos bens, com uma mesma função de produção, com retornos constantes à escala e utilizando capital e trabalho como fatores de produção, diferenças no nível de renda per capita entre os países refletem diferenças no estoque de capital per capita entre os países. A lei dos rendimentos decrescentes implica que o produto marginal do capital deveria ser alto nos países onde o capital é relativamente escasso e baixo nos países onde o capital é relativamente abundante. Considere uma economia pequena e aberta onde a produção $(Y)$ resulta da combinação dos insumos capital $(K)$ e trabalho $(L)$ a um dado nível de Produtividade Total dos Fatores $\left(A_{t}\right)$ :

$$
Y_{t}=A_{t} F\left(K_{t}, L_{t}\right) ; F_{K}(.)>0 ; F_{L}(.)>0 ; F_{K K}(.)<0 ; F_{L L}(.)<0
$$

Se todos os países compartilham a mesma função de produção, a perfeita mobilidade de capitais implica convergência instantânea da taxa de retorno do capital entre os países. Então, para os países $i$ e $j$,

$$
A_{t} f^{\prime}\left(k_{i t}\right)=r_{t}=A_{t} f^{\prime}\left(k_{j t}\right)
$$

Onde $f($.$) é a função de produção líquida de depreciação em termos per capita e k$ é o estoque de capital per capita. Em um ambiente de livre mobilidade de capitais e mercados financeiros eficientes, o retorno decrescente ao capital implica que, durante o processo de transição, o capital deveria fluir de países onde o estoque de capital per capita é alto e o retorno marginal do capital é baixo (países desenvolvidos) para países onde o estoque de capital per capita é baixo e o retorno marginal do capital é alto (países em desenvolvimento) até a equalização da taxa de retorno do capital entre os países (Lucas, 1990).

Lucas (1990) compara os Estados Unidos e a Índia em 1988 e mostra que o retorno do capital na Índia seria 58 vezes o retorno do capital nos Estados Unidos com base nesse modelo neoclássico. Em um ambiente de livre mobilidade de capitais e mercados financeiros completos, esse modelo implicaria fluxos de capitais em grandes magnitudes dos Estados Unidos e de outros países desenvolvidos para a Índia e outros países em desenvolvimento. Lucas (1990) considerou um puzzle a pequena magnitude observada dos fluxos de capitais direcionados aos países em desenvolvimento.

\subsection{As evidências}

Com base no modelo neoclássico, em uma amostra composta de países desenvolvidos e países em desenvolvimento, deveria existir uma correlação negativa entre o nível inicial do PIB per capita e a entrada de capitais no período posterior: o capital deveria fluir para países pobres, onde o nível inicial do PIB per 
capita é baixo, o nível inicial do estoque de capital per capita é baixo e o retorno marginal do capital é alto (Clemens; Williamson, 2004; Alfaro et al., 2008).

Os Gráficos 2 e 3 mostram os resultados de duas regressões para uma amostra de 105 países, 22 países desenvolvidos e 83 países em desenvolvimento: i) Estoque Total de Obrigações per capita (variável explicada) e PIB per capita; ii) Fluxo Total de Capitais per capita (variável explicada) e PIB per capita. O coeficiente associado ao PIB per capita é positivo e estatisticamente significativo a $1 \%$ nas duas regressões. A relação positiva entre uma medida de entrada de capitais e uma medida de renda per capita é evidência de que os capitais fluem para os países ricos e caracteriza o puzzle no padrão dos fluxos de capitais (Clemens; Williamson, 2004; Alfaro et al., 2008).

\section{Gráfico 2}

Estoque total de obrigações per capita e PIB per capita

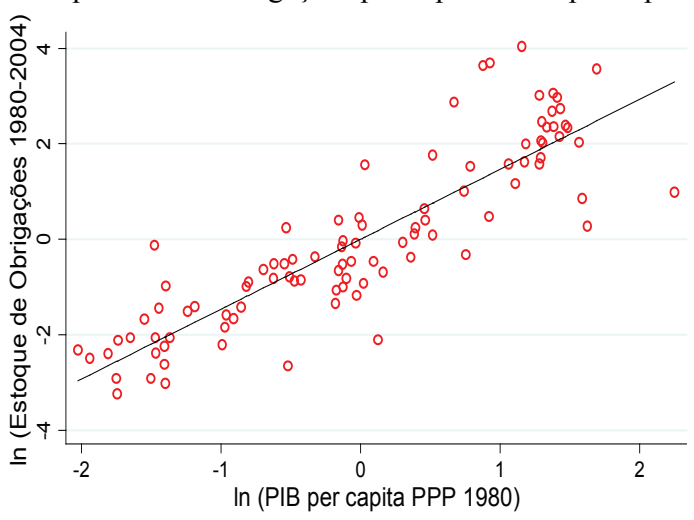

coef $=1.4634156$, (robust) se $=.0895191, t=16.35$, R-sq. $=0.76$

Fonte: Lane e Milesi-Ferretti (2007) e World

Development Indicators (2007). Elaboração própria.

Gráfico 3

Fluxo total de capitais per capita e PIB per capita

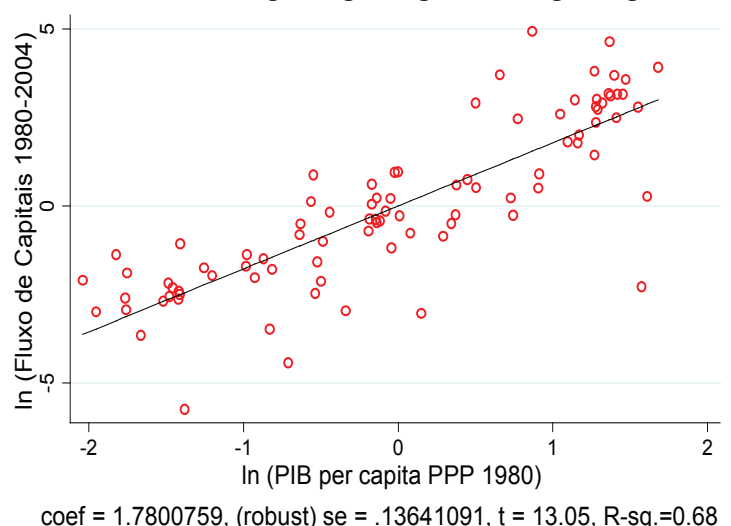

Fonte: International Financial Statistics (2008) e World Development Indicators (2007). Elaboração própria. 
Os Gráficos 4, 5, 6 e 7 mostram os resultados de quatro regressões para uma amostra de 105 países, 22 países desenvolvidos e 83 países em desenvolvimento. O coeficiente associado ao PIB per capita é positivo e estatisticamente significativo a $1 \%$ nas quatro regressões e é maior nas regressões apresentadas nos gráficos 4 e 5 onde as variáveis dependentes são fluxo e estoque de Equity. Portanto, mesmo quando se consideram distintas categorias de fluxos de capitais e estoques de obrigações, o puzzle permanece: os capitais fluem para os países ricos ${ }^{2}$.

Gráfico 4

Estoque de obrigações equity per capita e PIB per capita

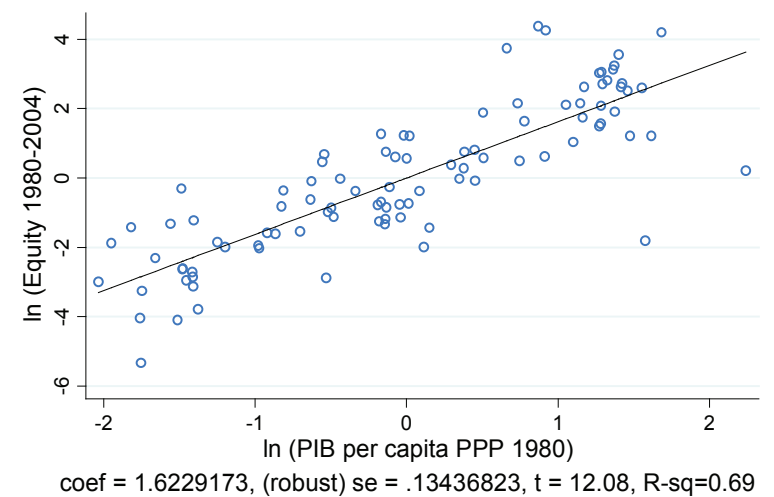

Fonte: Lane e Milesi-Ferretti (2007) e World Development Indicators (2007). Elaboração própria.

\section{Gráfico 5}

Fluxo de capitais equity per capita e PIB per capita

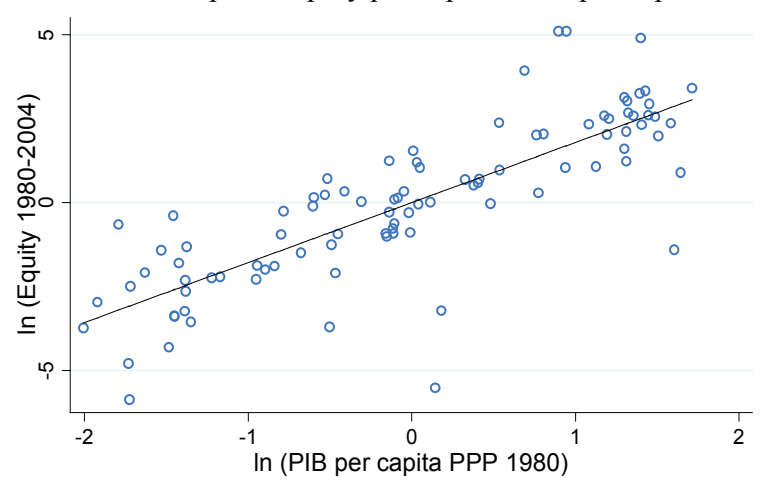

coef $=1.7892011$, (robust) $s e=.13304612, t=13.45$, R-sq. $=0.65$

Fonte: International Financial Statistics (2008) e World Development Indicators (2007). Elaboração própria.

(2) Prasad et al. (2007) e Henry (2007 b) admitem que, no modelo neoclássico, não há distinção entre diferentes categorias de fluxos de capitais, tratando-as como uma categoria homogênea, mas sugerem que o puzzle no padrão dos fluxos de capitais é resultado, principalmente, do padrão do fluxo e estoque de Debt. 
Gráfico 6

Estoque de obrigações debt per capita e PIB per capita

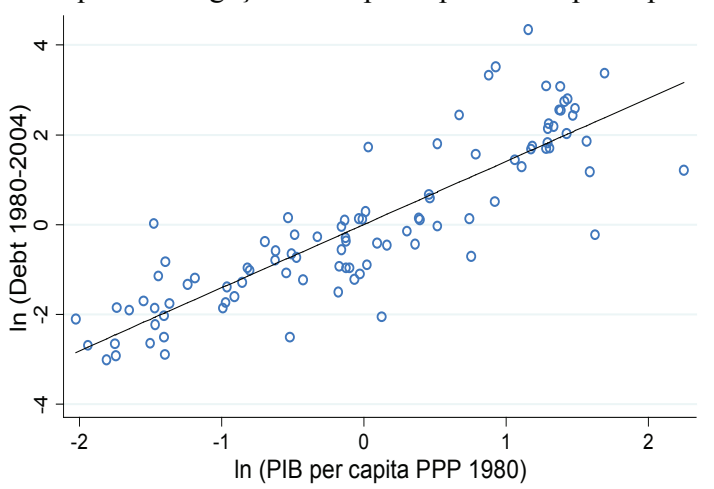

coef $=1.4067145$, (robust) se $=.08847091, t=15.9, \mathrm{R}$-sq. $=0.74$

Fonte: Lane e Milesi-Ferretti (2007) e World

Development Indicators (2007). Elaboração própria.

Gráfico 7

Fluxo de capitais debt per capita e PIB per capita

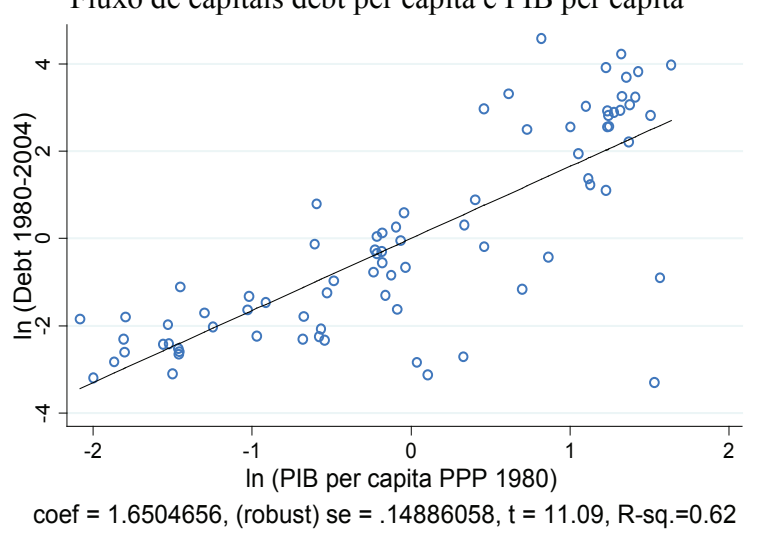

Fonte: International Financial Statistics (2008) e World Development Indicators (2007). Elaboração própria.

Com base no modelo neoclássico, os países desenvolvidos, onde se supõe que o capital é relativamente abundante e o retorno marginal do capital é baixo, deveriam ser exportadores líquidos de capitais, e os países em desenvolvimento, onde se supõe que o capital é relativamente escasso e o retorno marginal do capital é alto, deveriam ser importadores líquidos de capitais (Prasad et al., 2007; Henry, 2007a, 2007b).

O Gráfico 8 mostra o saldo em conta-corrente para 22 países desenvolvidos e 83 países em desenvolvimento. O saldo acumulado para o grupo de países desenvolvidos é de US\$ 564,421 bilhões no período 1980-1997, US\$ 3.654,573 bilhões no período 1998-2008 e US\$ 4.218,994 bilhões no período 1980-2008. O saldo acumulado para o grupo de países em desenvolvimento é de US\$ 819,937 
bilhões no período 1980-1997, US\$ 3.321,586 bilhões no período 1998-2008 e US\$ 2.501,649 no período 1980-2008. Portanto, o grupo de países desenvolvidos é importador líquido de capitais, e o grupo de países em desenvolvimento é exportador líquido de capitais.

Gráfico 8

Conta-corrente (US\$ bilhões) - Padrão global

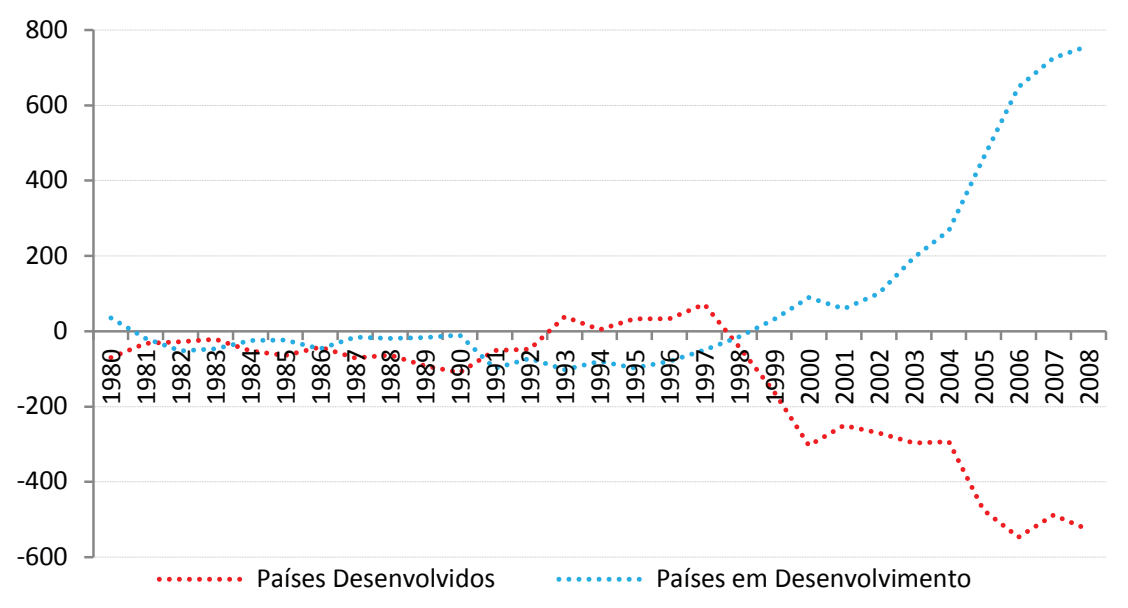

Fonte: World Economic Outlook Database (2009). Elaboração própria.

Os dados apresentados nesta subseção sugerem que a incoerência entre o padrão observado dos fluxos de capitais e o padrão previsto dos fluxos de capitais com base no modelo neoclássico é mais profunda do que a identificada por Lucas (1990): mais claramente no período recente, os capitais fluem, em termos líquidos, dos países em desenvolvimento para os países desenvolvidos.

\section{Por que os capitais fluem pouco para os países em desenvolvimento?}

\subsection{A teoria}

No âmbito da abordagem convencional, existem dois conjuntos de explicações para o puzzle. Esses dois conjuntos de explicações modificam pressupostos do modelo neoclássico e enfatizam a importância de imperfeições no mercado financeiro e diferenças de fundamentos entre países como essenciais para a explicação do padrão dos fluxos de capitais entre países desenvolvidos e em desenvolvimento.

O primeiro conjunto de explicações para o puzzle são imperfeições no mercado financeiro, notadamente, ineficiências resultantes da existência de assimetria de informação e problemas de enforcement de contratos. 
A assimetria de informação resultaria em distorções na alocação global de poupança como resultado de seleção adversa, risco moral e comportamento de manada. Sob o pressuposto de existência de assimetria de informação, o mercado internacional de capitais não aloca o capital de maneira eficiente e, portanto, "[...] under asymmetric information, the main implications of the neoclassical model regarding the capital flows tend not to hold" (Alfaro et al., 2008, p. 352).

Questões relativas ao enforcement de contratos no mercado internacional de capitais, especificamente, a existência de risco soberano e risco político, definidos por Obstfeld e Rogoff (1996, p.349) como "[...] any situation where a sovereign defaults on loan contracts with foreigners seizes foreign assets located within its borders, or prevents domestic residents from fully meeting obligations to foreign contracts", seriam uma explicação.

O segundo conjunto de explicações para o puzzle constitui-se de diferenças entre os países relativas aos fundamentos, especificamente, a existência de outros fatores de produção além de capital e trabalho, distorções geradas por políticas governamentais e diferentes ambientes institucionais.

A existência de um terceiro fator de produção - capital humano -, ignorado no modelo neoclássico, pode resultar em externalidades para o retorno marginal do capital. Se o estoque e a qualidade do capital humano geram externalidades positivas para o retorno marginal do capital, menos capital tenderia a fluir para países onde a dotação e a qualidade do capital humano é baixa (Lucas, 1990). Então, se a função de produção é de fato dada por:

$$
Y_{t}=A_{t} F\left(K_{t}, H_{t}, L_{t}\right)
$$

Onde $H_{t}$ representa outro fator que afeta o processo de produção, então, a equação (2) representa inadequadamente as implicações do modelo para o padrão dos fluxos de capitais. Desse modo, para os países $i$ e $j$, o verdadeiro retorno seria:

$$
A_{t} f^{\prime}\left(k_{i t}, h_{i t}\right)=r_{t}=A_{t} f^{\prime}\left(k_{j t}, h_{j t}\right)
$$

Políticas governamentais podem gerar distorções que resultam em impedimento para os fluxos de capitais e para a convergência da taxa de retorno entre os países: i) diferenças entre os países quanto à política tributária; ii) quanto às políticas inflacionárias; e iii) existência de controles de capitais. $\mathrm{O}$ efeito dessas distorções pode ser modelado assumindo que o governo tributa o capital à taxa $\tau$, que difere entre os países (ALFARO et al., 2008). Para os países $i$ e $j$, o verdadeiro retorno seria:

$$
A_{t} f^{\prime}\left(k_{i t}\right)\left(1-\tau_{i t}\right)=r_{t}=A_{t} f^{\prime}\left(k_{j t}\right)\left(1-\tau_{j t}\right)
$$

Por fim, diferenças entre os países relativas ao ambiente institucional, que resultam em incentivos distintos para a acumulação de capital físico, acumulação 
de capital humano, adoção de novas tecnologias e alocação eficiente de recursos. As diferenças entre os países relativas ao ambiente institucional podem ser modeladas como diferenças no nível de Produtividade Total dos Fatores entre os países, ou seja, no parâmetro $A_{t}$ (Obstfeld; Taylor, 2004; Alfaro et al., 2008; Acemoglu, 2009) ${ }^{3}$. Então, para os países $i$ e $j$, o verdadeiro retorno seria:

$$
A_{i t} f^{\prime}\left(k_{i t}\right)=r_{t}=A_{j t} f^{\prime}\left(k_{j t}\right)
$$

Esses seriam os elementos que explicariam o puzzle no padrão dos fluxos de capitais, porque os capitais não fluem para os países em desenvolvimento como previsto pelo modelo neoclássico.

\subsection{As evidências}

\section{Estratégia empírica}

A investigação econométrica acerca do padrão dos fluxos de capitais e estoques de obrigações tem como objetivo responder à seguinte questão: diferenças entre os países relativas ao ambiente institucional, estoque de capital humano, integração financeira, política macroeconômica e desenvolvimento financeiro explicam o puzzle no padrão dos fluxos de capitais? Será adotada a seguinte estratégia empírica (Clemens; Williamson, 2004; Alfaro et al., 2008):

i) em uma equação estimada onde a variável dependente é uma medida de entrada de capitais e a variável explanatória é o nível inicial do PIB per capita, o que caracteriza o puzzle no padrão dos fluxos de capitais é o coeficiente positivo e estatisticamente significativo associado ao nível inicial do PIB per capita;

ii) para as equações estimadas onde a variável dependente é uma medida de entrada de capitais e a variável explanatória é o nível inicial do PIB per capita, serão incluídas variáveis de controle para o ambiente institucional, estoque de capital humano, abertura financeira, política macroeconômica e desenvolvimento financeiro;

(3) Conforme Acemoglu (2009, p. 120): "Economic institutions are important because they influence the structure of economic incentives in society. Without property rights, individuals will not have the incentive to invest in physical or human capital or adopt more efficient technologies. Economic institutions are also important because they ensure the allocation of resources to their most efficient use". Para Gertler e Rogoff (1990), a explicação para o puzzle seria a assimetria de informação resultante do baixo desenvolvimento do mercado financeiro doméstico. Conforme Reinhart e Rogoff (2004, p. 56-57): “Thus, the key explication to the 'paradox' of why so little capital flows to poor countries may be quite simple: Countries that do not repay their debts have a relatively difficult time borrowing from the rest of the world. The fact that so many poor countries are in default on their debts, that so little funds are channeled through equity, and that overall private lending rises more than proportionally with wealth, all strongly support the view that credit markets and political risk are the main reasons why we do not see more capital flows to developing countries". Henry (2007a) argumenta que é difícil distinguir problemas de assimetria de informação, risco político e ambiente institucional inadequado. 
iii) se o coeficiente associado ao nível inicial do PIB per capita deixar de ser positivo e estatisticamente significativo, existe evidência de que o puzzle no padrão dos fluxos de capitais é explicado por diferenças entre os países relativas ao ambiente institucional, estoque de capital humano, integração financeira, política macroeconômica e desenvolvimento financeiro.

Serão adotadas duas abordagens econométricas: i) cross-section, de maneira a explorar informações contidas na variação dos dados entre países; ii) dados em painel, de maneira a explorar informações contidas na variação dos dados entre países e ao longo do tempo. As variáveis dependentes são: i) Fluxo Total de Capitais per capita, Fluxo de Capitais Equity per capita e Fluxo de Capitais Debt per capita; e ii) Estoque Total de Obrigações per capita, Estoque de Obrigações Equity per capita e Estoque de Obrigações Debt per capita. As variáveis explanatórias são: i) PIB per capita, que controla para o nível inicial de renda per capita; ii) Perfil, Burocracia, Corrupção e Lei \& Ordem, que controlam para o ambiente institucional; iii) Capital Humano, que controla para o estoque de capital humano; iv) CIIFI, que controla para o nível de integração financeira; v) Governo e Inflação, que controlam para a política macroeconômica; e vi) Crédito, que controla para o nível de desenvolvimento financeiro. As definições detalhadas das variáveis e amostras estão apresentadas, respectivamente, nos Quadros A1 e A2, em Apêndice.

\section{O padrão dos fluxos de capitais em um cross-section de países}

Serão estimadas equações especificadas como um modelo linear e escritas para cada país da amostra como:

$$
y_{i}=\mathbf{x}_{i}^{\prime} \beta+u_{i} \quad i=1,2, \ldots, N
$$

Onde $y_{i}$ é a variável dependente, $\mathbf{x}_{i}^{\prime}$ é um vetor de variáveis explanatórias de dimensão $k \times 1, \beta$ é um vetor de parâmetros de dimensão $k \times 1$ e $u_{i}$ é o termo de erro. As equações serão estimadas por Mínimos Quadrados Ordinários (MQO). As variáveis dependentes Fluxo Total de Capitais per capita, Fluxo de Capitais Equity per capita, Fluxo de Capitais Debt per capita, Estoque Total de Obrigações per capita, Estoque de Obrigações Equity per capita e Estoque de Obrigações Debt per capita são calculadas como média para o período 1980-2004. A variável explanatória PIB per capita é calculada como nível em 1980, e as variáveis explanatórias Perfil, Burocracia, Corrupção, Lei \& Ordem, Capital Humano, CIIFI, Governo, Inflação e Crédito são calculadas como média para o período 1980-2004. Dessa maneira, tem-se uma observação para cada país da amostra de modo que a estrutura dos dados é cross-section.

Na Tabela A3, são apresentadas 15 equações estimadas: i) nas colunas 1.11.5, a variável dependente é Fluxo Total de Capitais per capita; ii) nas colunas 2.1- 
2.5, a variável dependente é Fluxo de Capitais Equity per capita; iii) nas colunas 3.1-3.5, a variável dependente é Fluxo de Capitais Debt per capita. Os resultados mostram que: i) o coeficiente associado ao PIB per capita é positivo e estatisticamente significativo nas equações das colunas 1.1, 2.1 e 3.1, usadas para construir os gráficos 3, 5 e 7, o que caracteriza o puzzle no padrão dos fluxos de capitais, e nas demais 12 equações; ii) os coeficientes associados às variáveis Perfil, Corrupção, Burocracia e Lei \& Ordem são positivos e estatisticamente significativos nas 12 equações; iii) o coeficiente associado à variável Capital Humano é positivo e estatisticamente significativo nas equações das colunas 2.22.5; iv) o coeficiente associado à variável CIIFI é positivo e estatisticamente significativo nas 12 equações; v) o coeficiente associado à variável Governo não é estatisticamente significativo, e o coeficiente associado à variável Inflação é negativo e estatisticamente significativo na equação da coluna 1.3 e nas equações das colunas $3.2-3.5$; vi) o coeficiente associado à variável Crédito é negativo e estatisticamente significativo nas equações das colunas 3.3 e 3.4.

Na Tabela A4 são apresentadas 15 equações estimadas: i) nas colunas 1.11.5, a variável dependente é Estoque Total de Obrigações per capita; ii) nas colunas 2.1-2.5, a variável dependente é Estoque de Obrigações Equity per capita; iii) nas colunas 3.1-3.5, a variável dependente é Estoque de Obrigações Debt per capita. Os resultados revelam que: i) o coeficiente associado ao PIB per capita é positivo e estatisticamente significativo nas equações das colunas $1.1,2.1$ e 3.1 , usadas na elaboração dos gráficos 2,4 e 6 , resultado que explicita o puzzle no padrão dos fluxos de capitais, e nas outras 12 equações; ii) o coeficiente associado à variável Perfil é positivo e estatisticamente significativo na equação da coluna 2.2, o coeficiente associado à variável Corrupção é positivo e estatisticamente significativo nas equações das colunas 1.3 e 2.3 , o coeficiente associado à variável Burocracia não é estatisticamente significativo e o coeficiente associado à variável Lei \& Ordem é positivo e estatisticamente significativo nas três equações; iii) o coeficiente associado à variável Capital Humano é positivo e estatisticamente significativo nas equações das colunas 1.4 e 2.2-2.5; iv) o coeficiente associado à variável CIIFI é positivo e estatisticamente significativo em 11 equações; v) o coeficiente associado à variável Governo não é estatisticamente significativo, e o coeficiente associado à variável Inflação é negativo e estatisticamente significativo nas equações das colunas 1.2-1.4, 2.3 e 3.2-3.4 e; vi) o coeficiente associado à variável Crédito não é estatisticamente significativo.

Esses resultados sugerem a seguinte interpretação: i) o ambiente institucional e o nível de integração financeira são relevantes para o padrão dos fluxos de capitais e estoques de obrigações, de maneira que uma melhora no ambiente institucional e um aumento no nível de integração financeira resultariam em um aumento nos fluxos de capitais e estoques de obrigações; ii) o estoque de capital humano importa para o padrão do fluxo de capitais e estoque de obrigações 
Equity, de forma que um aumento no estoque de capital humano resultaria em um aumento no fluxo de capitais e estoque de obrigações Equity; iii) existe pouca evidência de que a política macroeconômica seja relevante para o padrão dos fluxos de capitais e estoques de obrigações; iv) não há evidência de que o nível de desenvolvimento financeiro importe para o padrão dos fluxos de capitais e estoque de obrigações. Por fim, o coeficiente associado ao PIB per capita é positivo e estatisticamente significativo nas 30 equações, de modo que o puzzle permanece: diferenças entre os países relativas ao ambiente institucional, estoque de capital humano, integração financeira, política macroeconômica e desenvolvimento financeiro não explicam o puzzle.

Stulz (2005) e Alfaro et al. (2008) sugerem que fluxos de capitais e estoques de obrigações podem beneficiar os países na forma de uma melhoria no ambiente institucional. Dessa forma, nas equações estimadas e apresentadas nas abelas A3 e A4, as variáveis que controlam para diferenças entre os países relativas ao ambiente institucional seriam endógenas, de modo que o estimador MQO seria inconsistente e os coeficientes estimados seriam viesados. Para lidar com a possível endogeneidade, será adotado o seguinte procedimento: i) obter instrumentos para as variáveis que controlam para o ambiente institucional e realizar estimações por meio de variáveis instrumentais; ii) após as estimações por meio de variáveis instrumentais, testar se as variáveis que controlam para o ambiente institucional são endógenas e se os instrumentos são válidos e relevantes; iii) se as variáveis que controlam para o ambiente institucional forem endógenas, o estimador MQO é inconsistente, tornando necessário um procedimento de variáveis instrumentais; iv) se as variáveis que controlam para o ambiente institucional não forem endógenas, $\mathrm{o}$ estimador MQO é consistente e eficiente, tornando desnecessário um procedimento de variáveis instrumentais ${ }^{4}$.

(4) A obtenção de instrumentos para as variáveis que controlam para o ambiente institucional está baseada em três abordagens. A primeira utiliza variáveis que captam a influência da Europa Ocidental entre os países do mundo e tem por base o argumento de que uma maior influência está associada a um ambiente institucional mais desenvolvido, de modo que a variável utilizada como instrumento é a proporção da população de cada país que fala inglês, denominada English Language (Hall; Jones, 1999). A segunda utiliza variáveis que distinguem os países em relação à origem do sistema legal e tem por base o argumento de que o sistema legal anglo-saxão (English Common Law) está associado a um maior desenvolvimento do ambiente institucional, de maneira que a variável utilizada como instrumento é uma dummy com 1 para países cuja origem do sistema legal é anglo-saxã e 0 para países cuja origem do sistema legal não é anglo-saxã, denominada English Law (La Porta et al., 1999, 2008; Glaeser et al., 2004). A terceira utiliza variáveis que captam as condições enfrentadas pelos colonizadores nas ex-colônias e tem por base o argumento segundo o qual, nas localidades onde os colonizadores encontraram condições adversas (disease) para o povoamento, foram introduzidas instituições pouco desenvolvidas, que persistiram ao longo do tempo, sendo assim, a variável utilizada como instrumento é a taxa de mortalidade enfrentada pelos colonizadores nas ex-colônias, denominada Settler Mortality (Acemoglu et al., 2001; Acemoglu; Johnson, 2005). As variáveis English Language e English Law estão disponíveis para a amostra utilizada para as estimações nas Tabelas A1 e A2, e a variável Settler Mortality está disponível para 46 países da amostra utilizada para as estimações nas Tabelas A1 e A2. 
As Tabelas A1.1 e A2.1 apresentam resultados das estimações pelo Método dos Momentos Generalizados (GMM) para especificações idênticas às equações estimadas por MQO e apresentadas nas Tabelas A1 e A2, utilizando English Language e English Law como instrumentos. As Tabelas A1.2 e A2.2 apresentam resultados das estimações por GMM para especificações idênticas às equações estimadas por MQO e apresentadas nas Tabelas A1 e A2, utilizando English Language, English Law e Settler Mortality como instrumentos. Em cada tabela, são apresentados: teste de endogeneidade (Estat Endog) para as variáveis que controlam para o ambiente institucional, teste de sobreidentificação (Estat Overid) para a validade dos instrumentos e testes de instrumentos fracos (Minimum Eigenvalue Statistic, 2SLS Relative Bias, 2SLS Size of Nominal 5\% Wald Test) para a relevância dos instrumentos.

Os resultados apresentados mostram que: i) o teste de endogeneidade não rejeita a hipótese nula de que as variáveis que controlam para o ambiente institucional são exógenas; ii) o teste de sobreidentificação não rejeita a hipótese nula de que os instrumentos são válidos; iii) os testes de instrumentos fracos não rejeitam a hipótese nula de que os instrumentos são fracos. Como há evidência de que as variáveis Perfil, Corrupção, Burocracia e Lei \& Ordem são exógenas, reporta-se, nas Tabelas A1.1, A2.1, A1.2 e A2.2, apenas os testes de endogeneidade, validade e relevância de instrumentos, já que, nessa situação, o estimador MQO é consistente e eficiente. O estimador GMM, nessa situação, é consistente, mas menos eficiente que o estimador MQO. Ademais, mesmo que as variáveis que controlam para o ambiente institucional fossem endógenas, como há evidências de instrumentos fracos, o estimador GMM resultaria em viés e imprecisão na estimação dos parâmetros, possivelmente mais severos que o estimador MQO (Wooldridge, 2010; Baum, 2006; Baum et al., 2003, 2007; Cameron; Trivedi, 2005, 2009; Stock; Yogo, 2005) ${ }^{5}$.

\section{O padrão dos fluxos de capitais em um painel de países}

Serão estimadas equações especificadas como um modelo linear e escritas para cada país e cada período como:

$$
y_{i, t}=\mathbf{x}_{i, t}^{\prime} \beta+\eta_{i}+\varepsilon_{i, t} \quad i=1,2, \ldots, N \text { e } t=1,2, \ldots, T
$$

Onde $y_{i, t}$ é a variável dependente, $\mathbf{x}_{i, t}^{\prime}$ é um vetor de variáveis explanatórias de dimensão $k \times 1$ que variam ao longo do tempo e entre países, $\beta$ é um vetor de

(5) Com o objetivo de investigar se os resultados apresentados nas Tabelas A1, A2, A1.1, A2.2, A3.1 e A3.2 são sensíveis à existência de possíveis outliers, todos os procedimentos econométricos foram realizados, excluindo da amostra as observações para as quais a estatística Dfits sugere que sejam influentes. Os resultados encontrados, não reportados aqui por falta de espaço, reforçam as evidências e a interpretação apresentadas ao longo da subseção 4.2, ou seja, os resultados encontrados não se devem à existência de potenciais outliers. 
parâmetros de dimensão $k \times 1$ e $\varepsilon_{i, t}$ é o erro idiossincrático, que varia ao longo do tempo e entre países. $\mathrm{O}$ termo $\eta_{i}$ varia entre os países, é constante ao longo do tempo e capta as características não observáveis específicas a cada país, ou seja, controla para a heterogeneidade não observável entre países. A natureza da relação entre $\eta_{i}$ e $\mathbf{x}_{i, t}^{\prime}$ permite a utilização de dois estimadores (Cameron; Trivedi, 2005; Baltagi, 2008; Wooldridge, 2010).

Se não existe relação de qualquer natureza entre $\eta_{i}$ e $\mathbf{x}_{i, t}^{\prime}$, ou seja, se $\operatorname{Cov}\left(\mathbf{x}_{i, t}^{\prime}, \eta_{i}\right)=0$, tem-se um modelo de efeitos aleatórios de maneira que o Estimador de Efeitos Aleatórios é apropriado. Se existe relação de qualquer natureza entre $\eta_{i}$ e $\mathbf{x}_{i, t}^{\prime}$, ou seja, se $\operatorname{Cov}\left(\mathbf{x}_{i, t}^{\prime}, \eta_{i}\right) \neq 0$, tem-se um modelo de efeitos fixos de maneira que o Estimador de Efeitos Fixos é apropriado. A decisão quanto ao estimador apropriado tem como base o Teste de Hausman, cuja hipótese nula é de que não há relação de qualquer natureza entre $\eta_{i}$ e $\mathbf{x}_{i, t}^{\prime}$, ou seja, $\operatorname{Cov}\left(\mathbf{x}_{i, t}^{\prime}, \eta_{i}\right)=$ 0 .

As variáveis dependentes Fluxo Total de Capitais per capita, Fluxo de Capitais Equity per capita, Fluxo de Capitais Debt per capita, Estoque Total de Obrigações per capita, Estoque de Obrigações Equity per capita e Estoque de Obrigações Debt per capita são calculadas como média para cada período de cinco anos. As variáveis explanatórias PIB per capita e Capital Humano são calculadas como o nível no ano inicial de cada período de cinco anos, e as variáveis explanatórias Perfil, Burocracia, Corrupção, Lei \& Ordem, CIIFI, Governo, Inflação e Crédito são calculadas como média para cada período de cinco anos. Dessa forma, temos cinco observações para cada país da amostra, uma para cada quinquênio (1980-1984, 1985-1989, 1990-1994, 1995-1999, 2000-2004), de modo que a estrutura dos dados é em painel. Essa estrutura de dados permite controlar para a heterogeneidade não observável entre países, explorar informações contidas na variação dos dados entre países e ao longo do tempo e, ao fazer médias quinquenais dos dados, minimizar os efeitos de flutuações de curto prazo.

Na Tabela A3 são apresentadas 15 equações: i) nas colunas 1.1-1.5, a variável dependente é Fluxo Total de Capitais per capita; ii) nas colunas 2.1-2.5, a variável dependente é Fluxo de Capitais Equity per capita; iii) nas colunas 3.1-3.5, a variável dependente é Fluxo de Capitais Debt per capita. Os resultados evidenciam que: i) o coeficiente associado ao PIB per capita é positivo e estatisticamente significativo nas equações das colunas 1.1, 2.1 e 3.1 , o que caracteriza o puzzle no padrão dos fluxos de capitais, e em 11 das demais equações; ii) o coeficiente associado à variável Perfil é positivo e estatisticamente significativo nas equações das colunas 1.2 e 2.2 , o coeficiente associado à variável Lei \& Ordem é positivo e estatisticamente significativo na equação da coluna 2.5 e os coeficientes associados às variáveis Corrupção e Burocracia não são estatisticamente significativos; iii) o coeficiente associado à variável Capital 
Humano é positivo e estatisticamente significativo nas equações das colunas 2.22.5 ; iv) o coeficiente associado à variável CIIFI é positivo e estatisticamente significativo nas 12 equações; v) os coeficientes associados às variáveis Governo e Inflação são negativos e estatisticamente significativos nas equações das colunas 2.2-2.5, e o coeficiente associado à variável Governo é positivo e estatisticamente significativo nas equações das colunas 3.2 e 3.5 ; vi) o coeficiente associado à variável Crédito é positivo e estatisticamente significativo nas equações das colunas 1.2-1.5 e 3.4 .

Na Tabela A4 são apresentadas 15 equações: i) nas colunas 1.1-1.5, a variável dependente é Estoque Total de Obrigações per capita; ii) nas colunas 2.12.5, a variável dependente é Estoque de Obrigações Equity per capita; iii) nas colunas 3.1-3.5, a variável dependente é Estoque de Obrigações Debt per capita. Os resultados explicitam que: i) o coeficiente associado ao PIB per capita é positivo e estatisticamente significativo nas equações das colunas 1.1, 2.1 e 3.1 , o que caracteriza o puzzle no padrão dos fluxos de capitais, e nas outras 12 equações; ii) os coeficientes associados às variáveis Perfil, Corrupção, Burocracia e Lei \& Ordem não são estatisticamente significativos; iii) o coeficiente associado à variável Capital Humano é positivo e estatisticamente significativo nas 12 equações; iv) o coeficiente associado à variável CIIFI é positivo e estatisticamente significativo em 7 equações; v) o coeficiente associado à variável Governo não é estatisticamente significativo, e o coeficiente associado à variável Inflação é negativo e estatisticamente significativo nas equações das colunas 1.4 e 2.2-2.5; vi) o coeficiente associado à variável Crédito é positivo e estatisticamente significativo nas equações das colunas 1.2-1.5 e 3.2-3.5.

Os resultados para os modelos de dados em painel sugerem a seguinte interpretação: i) não há evidências de que o ambiente institucional importe para o padrão dos fluxos de capitais; ii) o estoque de capital humano importa para o padrão do fluxo de capitais e estoque de obrigações, especialmente para fluxo e estoque de Equity, de maneira que um aumento no estoque de capital humano resultaria em um aumento no fluxo de capitais e estoque de obrigações Equity; iii) o nível de integração financeira é relevante para o padrão dos fluxos de capitais e estoques de obrigações de modo que um aumento no nível de integração financeira resultaria em aumento nos fluxos de capitais e estoques de obrigações; iv) a evidência acerca da relevância da política macroeconômica para o padrão dos fluxos de capitais e estoques de obrigações é escassa; v) existe pouca evidência de que o nível de desenvolvimento financeiro importe para o padrão dos fluxos de capitais e estoque de obrigações. Como o coeficiente associado ao PIB per capita é positivo e estatisticamente significativo em 29 das 30 equações, diferenças entre os países relativas ao ambiente institucional, estoque de capital humano, integração 
financeira, política macroeconômica e desenvolvimento financeiro não explicam o puzzle.

Os resultados apresentados nesta subseção são robustos em relação a diferentes categorias de fluxos de capitais e estoques de obrigações (Total, Equity e Debt) e diferentes metodologias econométricas (cross-section e dados em painel).

\subsection{Discussão}

Os resultados apresentados e discutidos ao longo deste artigo estão relacionados a um conjunto de trabalhos que investiga o padrão dos fluxos de capitais e sua importância para o desempenho econômico dos países:

Primeiro, estão relacionados à literatura que investiga a existência de diferencial de retorno para o capital entre países desenvolvidos e países em desenvolvimento. Caselli e Feyrer (2007) estimam o retorno marginal do capital para os países desenvolvidos e países em desenvolvimento e encontram evidências de que o diferencial de retorno entre os dois grupos de países é limitado. Chirinko e Mallick (2008) estimam o retorno marginal do capital para os países desenvolvidos e países em desenvolvimento e encontram evidências de que o retorno é substancialmente maior para o grupo de países em desenvolvimento em relação ao grupo de países desenvolvidos. Dessa forma, a literatura sobre diferencial de retorno para o capital entre países não é conclusiva.

Segundo, estão relacionados à literatura que investiga o padrão dos fluxos de capitais. Clemens e Williamson (2004) documentam o puzzle no padrão dos fluxos de capitais no período 1870-1913 e, usando modelos para cross-section, encontram evidências econométricas de que diferenças entre os países relativas à dotação de capital humano, dotação de recursos naturais e características demográficas explicam o puzzle. Alfaro et al. (2008) documentam o puzzle utilizando dados para Fluxo de Capitais Equity no período 1970-2000 e, usando modelos para cross-section, apresentam evidências econométricas de que diferenças entre os países relativas ao ambiente institucional são relevantes para o padrão do Fluxo de Capitais Equity e explicam o puzzle.

Os resultados apresentados neste trabalho são distintos daqueles apresentados em Alfaro et al. (2008): não foram encontradas evidências de que diferenças entre países relativas ao ambiente institucional, ambiente macroeconômico, integração financeira, estoque de capital humano e desenvolvimento financeiro explicam o puzzle. Ademais, as evidências acerca da importância do ambiente institucional para o padrão dos fluxos de capitais e estoques de obrigações entre países e ao longo do tempo são frágeis. Por fim, os resultados são robustos em relação à utilização de uma ampla gama de categorias de fluxos de capitais e estoques de obrigações (Total, Equity e Debt) e de duas 
abordagens econométricas, a estimação de modelos para cross-section e dados em painel.

Terceiro, estão relacionados à literatura que investiga a importância da integração financeira e fluxos de capitais para o crescimento econômico. Entre os poucos trabalhos que encontram evidências de que a integração financeira estimula o crescimento econômico, destacam-se Quinn (1997) e Bekaert, Harvey e Lundablad (2005). Rodrik (1998), Rodrik e Subramanian (2009), Edison, Levine, Ricci e Sløk (2002), Carkovic e Levine (2005) e Prasad, Rajan e Subramanian (2007) não encontram evidências de que a integração financeira e os fluxos de capitais estimulem o crescimento econômico, mesmo em países com alto nível de desenvolvimento institucional, desenvolvimento financeiro, estabilidade macroeconômica e estoque de capital humano.

\section{Padrão dos fluxos de capitais: elementos para uma abordagem heterodoxa}

\subsection{Parábolas neoclássicas e controvérsia de Cambridge}

O ponto de partida para a teoria neoclássica do capital é a função de produção agregada, a qual exibe o que Samuelson (1962) denominou de três parábolas: i) o retorno real do capital (taxa de juros) é determinado pela propriedade técnica de produtividade marginal decrescente do capital; ii) uma maior quantidade de capital leva a uma menor produtividade marginal do capital e a um menor retorno real do capital (taxa de juros); iii) a distribuição de renda entre trabalhadores e capitalistas é explicada pela escassez relativa dos fatores de produção e produtos marginais. O questionamento apresentado por Robinson (1953-1954) iniciou um debate sobre a teoria do capital conhecido na literatura como Controvérsia de Cambridge ${ }^{6}$ : Como o capital é mensurado na função de produção agregada? A validade das três parábolas neoclássicas depende de um conceito de capital em termos físicos.

Como os bens de capital são heterogêneos, não podem ser mensurados e agregados em uma unidade física homogênea. A única forma de expressar o capital em uma única unidade agregada é em termos monetários. $\mathrm{O}$ valor do capital pode ser mensurado como o custo de produção ou como o valor presente do fluxo futuro de bens que gera. Nos dois casos, a mensuração envolve tempo e presume uma taxa de juros, determinada de maneira unidirecional pela quantidade de capital no modelo neoclássico, o que leva a uma circularidade. Ademais, essa circularidade causa efeitos Wicksell: i) mudanças no valor do capital quando mudam os valores da taxa de salário e da taxa de juros, embora as técnicas (relação capital-trabalho)

(6) Conforme Cohen e Harcourt (2003), os protagonistas dessa controvérsia estavam associados direta ou indiretamente a Cambridge, na Inglaterra (Piero Sraffa, Joan Robinson, Luigi Pasinetti e Pierangelo Garegnani), e Cambridge, nos Estados Unidos (Paul Samuelson, Robert Solow, Frank Hahn e Christopher Bliss). 
não mudem (efeito preço); ii) mudanças no valor do capital associadas a mudanças nas técnicas (relação capital-trabalho) quando a taxa de salário e a taxa de juros assumem valores diferentes (efeito real) (Harcourt, 1972; Cohen; Harcourt, 2003, 2005).

Os efeitos Wicksell criam os fenômenos denominados capital-reversing e reswitching. Com capital-reversing, uma menor relação capital-trabalho está associada a uma menor taxa de retorno do capital (taxa de juros). Ao comparar duas posições de equilíbrio de estado estacionário, a taxa de retorno do capital (taxa de juros) é menor na posição onde o capital é mais escasso. Capital-reversing implica a possibilidade da curva de demanda por capital não ser negativamente inclinada, violando as parábolas 2 e 3 . Com reswitching, a mesma técnica (relação capital-trabalho) é preferida em duas ou mais taxas de retorno do capital (taxa de juros) enquanto outras técnicas (relação capital-trabalho) são preferidas a taxas de retorno do capital (taxa de juros) intermediárias. Reswitching implica a possibilidade de a mesma técnica (relação capital-trabalho) estar associada a duas ou mais taxas de retorno do capital (taxa de juros), violando as parábolas 1 e 2 (Cohen; Harcourt, 2003, 2005; Lazzarini, 2011).

Como argumenta Kregel (2006, 2008), os resultados da Controvérsia de Cambridge sobre a teoria do capital representam uma crítica fundamental aos pressupostos teóricos subjacentes ao modelo neoclássico e a suas previsões relativas ao padrão dos fluxos de capitais. As previsões do modelo neoclássico relativas ao padrão dos fluxos de capitais entre países desenvolvidos e países em desenvolvimento têm como pressupostos: i) uma relação monotônica inversa entre a relação capital-trabalho e taxa de retorno do capital; ii) a relação capital-trabalho nos países desenvolvidos é maior do que a relação capital-trabalho nos países em desenvolvimento; iii) desse modo, com livre mobilidade de capitais e mercados financeiros eficientes, o capital deveria fluir, em termos líquidos, dos países desenvolvidos para os países em desenvolvimento, levando a uma alocação eficiente do capital mundial.

A mensuração do capital em uma unidade agregada em termos monetários envolve tempo, portanto, presume o conhecimento da taxa de retorno do capital, que, no modelo neoclássico, é determinada pela quantidade de capital. Como resultado, não é possível mensurar a relação capital-trabalho de forma não ambígua. Ademais, capital-reversing e reswitching implicam que uma menor relação capital-trabalho pode estar associada a uma menor taxa de retorno do capital e uma relação capital-trabalho pode estar associada a diferentes taxas de retorno do capital. Como resultado, é impossível estabelecer uma relação geral entre relação capital-trabalho e taxa de retorno do capital. Isso significa que o retorno do capital nos países em desenvolvimento pode ser menor que nos países desenvolvidos, mesmo se a relação capital-trabalho nos países em desenvolvimento 
for menor que a relação capital-trabalho nos países desenvolvidos (KREGEL, 2006, 2008).

\subsection{Mercados eficientes e não ergodicidade}

A hipótese de mercados eficientes afirma que, em qualquer ponto do tempo, os preços dos ativos refletem toda informação disponível, inclusive sobre os fundamentos. Fama $(1970,1991)$ distingue três formas de eficiência: i) a forma fraca estabelece que o preço corrente reflete toda a informação revelada pelos preços passados; ii) a forma semiforte estabelece que o preço corrente contém toda a informação pública sobre os elementos fundamentais que determinam os preços; iii) a forma forte estabelece que o preço corrente contém toda a informação econômica que pode ser conhecida. De acordo com essa hipótese, um mercado eficiente torna disponível aos agentes opções ótimas de investimento, levando a uma alocação eficiente do capital entre usos alternativos.

A hipótese de mercados eficientes pressupõe que o sistema econômico é ergódigo e assume que: i) existem fundamentos reais de mercado que são imutáveis no sentido de que não podem ser alterados pela ação humana; ii) esses fundamentos determinam as probabilidades condicionais de resultados futuros que são refletidos nos preços atuais dos ativos (Davidson, 2002). Em um processo estocástico ergódigo, a estimativa da distribuição de probabilidade condicional que governa os resultados presentes, calculada com base em um conjunto de dados observável, fornece informação estatística confiável sobre a distribuição de probabilidade condicional que governará os resultados futuros (Davidson, 2002).

Keynes $(1936,1937)$ argumenta que, em qualquer ponto do tempo, o futuro é incerto no sentido de que o lucro atuarial ou uma expectativa de ganho baseada em cálculos matemáticos confiáveis realizados de acordo com funções de distribuição de probabilidade existentes não pode ser obtido de algum conjunto de dados. Esse conceito de incerteza corresponde tecnicamente ao que os estatísticos matemáticos denominam de processo estocástico não ergódigo (Davidson, 2000). Ademais, em mercados financeiros, essa incerteza é ainda mais relevante, dado que, ao se negociarem ativos, se negociam, na verdade, recompensas futuras, a serem usufruídas sob condições que também só se revelarão no futuro (Carvalho; Sicsú, 2004).

Em um sistema econômico não ergódigo, a função do mercado financeiro não é alocar capital de forma eficiente entre usos alternativos, mas fornecer liquidez aos agentes econômicos: "In a nonergodic system, one can never expect whatever data set exists today to provide a reliable guide to future outcomes. In such world, markets cannot be efficient. Instead the primary function of financial markets is to provide liquidity" (Davidson, 2002, p. 187). Se a função do mercado 
financeiro não é alocar capital de forma eficiente entre usos alternativos, então não existe razão para esperar que, em um ambiente de livre mobilidade de capitais, o mercado financeiro internacional venha a alocar o capital de forma eficiente entre países desenvolvidos e em desenvolvimento ${ }^{7}$.

Ademais, em um ambiente econômico não ergódigo, um atributo relevante de qualquer ativo é a liquidez, isto é, a capacidade de conversão em moeda, com variações limitadas de valor, se e quando necessária. Um mercado financeiro fornece liquidez ao permitir a possibilidade de comprar e vender ativos em um mercado ordenado. Esse atributo do mercado, a ordenação, depende desse mercado não estar sujeito a variações bruscas de oferta e demanda e exige, portanto, uma instituição para regular os fluxos líquidos de capitais para dentro e fora do mercado. Em transações internacionais envolvendo diferentes moedas, um grau adequado de ordenação dos mercados pode ser obtido pela imposição de controles sobre os fluxos de capitais (Carvalho; Sicsú, 2004; Davidson, 2011).

\subsection{Inconversibilidade e assimetrias}

As características do sistema monetário e financeiro internacional que emergiu após o colapso do regime de Bretton Woods podem ser resumidas em quatro aspectos essenciais: livre mobilidade de capitais; regime de câmbio flexível; o dólar financeiro e fiduciário como moeda-chave; o caráter hierárquico e assimétrico (Tavares; Melin, 1997; Carneiro, 1999, 2008; Serrano, 2002; Prates, $2002,2005)$. Prates $(2002,2005)$ explicita a natureza centro-periferia do sistema monetário e financeiro internacional contemporâneo e identifica a existência de três assimetrias: i) assimetria monetária; ii) assimetria macroeconômica; iii) assimetria financeira.

A assimetria monetária refere-se à existência de uma hierarquia de moedas em âmbito internacional. A posição de cada moeda na hierarquia é definida com

(7) Davidson (2000, p. 1117) argumenta que: "The mantra of EMT (Efficient Market Theory) is 'the market knows best' how to optimally allocate scarce capital resources and promote maximum economic growth. Since the 1970s, this 'compelling' efficient market logic has provided the justification for nations to dismantle most of the post-war capital regulation in financial markets. The argument for this 'liberalization' of financial markets was that it would produce lower real costs of capital and higher output and productivity growth rates compared to the growth rates experienced between World War II and 1973 when international capital flow controls were practiced by most countries of the world, including the United States. In Keynes's General Theory the primary function of financial markets is to provide liquidity not efficiency, consequently real world international capital markets can never deliver, in either the short-run or the long-run, the results claimed by $E M T$ '. Especificamente a respeito do padrão dos fluxos de capitais, conforme Davidson (2006, p. 77): "Meanwhile, in the last quarter century, the floating exchange rate system, rather than encouraging the flow of capital from capital-rich developed nations to capital-poor less developed economies, has often encouraged capital flight in the opposite direction, thereby draining resources from the relatively poor nations of Africa and Latin America towards the richer ones. The result has been a growing global inequitable redistribution of income and wealth, thereby increasing the immiseration of the majority of the people on this planet". 
base no grau de conversibilidade, que é a capacidade de desempenhar as funções de meio de pagamento, unidade de conta e reserva de valor em âmbito internacional (Carneiro, 1999): i) o dólar desempenha integralmente as funções de meio de pagamento, unidade de conta e reserva de valor e é plenamente conversível; ii) as moedas dos demais países centrais desempenham, de forma secundária, as funções de meio de pagamento, unidade de conta e reserva de valor e são conversíveis; iii) as moedas dos países em desenvolvimento não desempenham as funções de meio de pagamento, unidade de conta e reserva de valor e são inconversíveis.

A conformação assimétrica do sistema monetário internacional define uma regra de formação de taxa de juros particularmente desfavorável aos países em desenvolvimento. As taxas de juros das moedas conversíveis e inconversíveis correspondem à taxa de juros da moeda plenamente conversível, acrescida de um prêmio de risco, tanto maior quanto menor for o grau de conversibilidade. A implicação é que os países em desenvolvimento emissores de moedas inconversíveis têm as taxas de juros mais elevadas. Ademais, a motivação para os fluxos de capitais é distinta conforme migram do país emissor da moeda plenamente conversível para os países emissores de moedas inconversíveis ou migram dos países emissores de moedas inconversíveis para o país emissor da moeda plenamente conversível (Carneiro, 2008).

Os capitais que migram do país emissor da moeda plenamente conversível para os países emissores de moedas inconversíveis, por se defrontarem com riscos mais elevados, exigem prêmios de risco maiores. Os capitais que migram dos países emissores de moedas inconversíveis para o país emissor da moeda plenamente conversível exigem prêmios de risco menores. Há uma assimetria neste último movimento porque uma parcela da riqueza dos residentes em países emissores de moedas inconversíveis buscará ativos denominados na moeda plenamente conversível, independentemente da remuneração desses ativos, pelo fato mesmo de estarem denominados na moeda plenamente conversível, que se constitui na representação geral e abstrata da riqueza no sistema globalizado (Carneiro, 2008).

A assimetria macroeconômica diz respeito à existência de diferentes graus de autonomia de política econômica para os países que compõem o sistema e deriva da assimetria monetária: i) o país emissor da moeda plenamente conversível tem maior grau de autonomia de política, o que permite vincular estreitamente a gestão da política monetária ao ciclo econômico doméstico; ii) os países centrais emissores de moedas conversíveis têm grau intermediário de autonomia de política, o que possibilita a utilização da política monetária para manejar o ciclo econômico doméstico; iii) os países em desenvolvimento emissores de moedas inconversíveis têm menor grau de autonomia de política, de modo que a ideia de trindade impossivel não se aplica perfeitamente (Prates, 2002, 2005; Ocampo, 2001). 
À assimetria do sistema monetário internacional sobrepõe-se a assimetria do sistema financeiro internacional, que engloba dois aspectos relativos aos fluxos de capitais para os países em desenvolvimento: i) não obstante o crescimento, os fluxos de capitais direcionados aos países em desenvolvimento representam uma fração marginal quando comparados aos fluxos de capitais direcionados aos países desenvolvidos; ii) os determinantes principais dos fluxos de capitais direcionados aos países em desenvolvimento são fatores externos, especialmente, a fase do ciclo econômico e o patamar das taxas de juros no país emissor da moeda plenamente conversível e demais países centrais emissores de moedas conversíveis (Prates, 2002, 2005; Ocampo, 2001) $)^{8}$.

Em síntese, esta seção esboça elementos para uma análise alternativa acerca do padrão dos fluxos de capitais. Primeiro, a crítica à teoria neoclássica do capital e à hipótese de mercados eficientes explicita a fragilidade dos fundamentos teóricos subjacentes ao modelo neoclássico e de suas previsões relativas ao padrão dos fluxos de capitais. Segundo, a natureza centro-periferia do sistema monetário e financeiro internacional realça as especificidades da inserção dos países em desenvolvimento. Considerando a impossibilidade de mensurar a intensidade de capital de forma não ambígua e de estabelecer uma relação geral entre intensidade de capital e taxa de retorno, os fundamentos pós-keynesianos acerca da operação dos mercados financeiros e a natureza centro-periferia do sistema monetário e financeiro internacional, não há porque supor que os capitais deveriam fluir, em termos líquidos, dos países desenvolvidos para os países em desenvolvimento e, portanto, o padrão observado para os fluxos de capitais não é um puzzle ${ }^{9}$.

\section{Considerações finais}

Este trabalho realiza uma investigação teórica e empírica sobre o padrão dos fluxos de capitais no período 1980-2004 para uma amostra de 105 países, 22 países desenvolvidos e 83 países em desenvolvimento. As evidências revelam o seguinte padrão: i) o caráter assimétrico do sistema financeiro internacional, com a participação marginal dos países em desenvolvimento, e a exacerbação dessa assimetria ao longo do tempo; ii) os capitais fluem pouco para os países em desenvolvimento e, no período recente, em termos líquidos, fluem dos países em

(8) A este respeito, Biancareli (2009, p. 10) argumenta que: "The level and conditions by which the private capital is available to developing countries are set by process beyond their control, or even their influence.

Hence, the power of domestic "fundamentals" - which can, of course, reinforce a trend already in progress or compensate its effects - are clearly subordinated to more important forces."

(9) Há convergência entre a análise desenvolvida nesta seção e a análise de Bibow (2008, p. 1): "The supposed paradox is that the developing world has increasingly come to pursue policies that resulted in current account surpluses and thus net capital exports - destined primarily for the capital-rich United States. The hypothesis put forward here is that systemic deficiencies in the international monetary and financial order have been the root cause behind today's situation". 
desenvolvimento para os países desenvolvidos; iii) diferenças entre os países relativas ao ambiente institucional, estoque de capital humano, integração financeira, política macroeconômica e desenvolvimento financeiro não explicam porque os capitais fluem pouco para os países em desenvolvimento.

O modelo neoclássico implica o papel fundamental da integração financeira e fluxos de capitais para a trajetória de acumulação de capital e crescimento econômico nos países em desenvolvimento: a ideia é que nesses países a acumulação de capital e o crescimento econômico são restringidos pelo baixo nível de poupança doméstica, de modo que a integração ao mercado financeiro internacional resultaria em importação líquida de capitais, aumento temporário na taxa de crescimento do estoque de capital, aumento temporário na taxa de crescimento do PIB per capita e aumento permanente no nível do PIB per capita. As evidências de que os países desenvolvidos são importadores líquidos de capitais e os países em desenvolvimento são exportadores líquidos de capitais são um desafio contundente a essa abordagem.

Encontra-se com frequência na literatura o argumento de que a integração financeira e os fluxos de capitais só resultariam em estímulo ao crescimento econômico em países onde existissem condições iniciais adequadas relativas ao ambiente institucional, estoque de capital humano, política macroeconômica e desenvolvimento financeiro. No entanto, não há evidências empíricas robustas na literatura acerca de benefícios da integração financeira e fluxos de capitais para o crescimento econômico, mesmo em países onde existem condições iniciais adequadas, coerente com as evidências apresentadas neste trabalho, ao mostrar que diferenças entre países relativas ao ambiente institucional, integração financeira, estoque de capital humano, política macroeconômica e desenvolvimento financeiro não explicam o puzzle no padrão dos fluxos de capitais.

Por fim, os resultados apresentados ao longo deste trabalho suscitam o esboço de uma explicação alternativa de inspiração heterodoxa para o padrão observado dos fluxos de capitais com base em três elementos essenciais: i) impossibilidade de mensurar a intensidade de capital de forma não ambígua e de estabelecer uma relação geral entre intensidade de capital e taxa de retorno; ii) não ergodicidade do sistema econômico e teoria da preferência pela liquidez; iii) natureza centro-periferia do sistema monetário e financeiro internacional. Nessa perspectiva, não há motivo para prever que em um mundo de livre mobilidade de capitais, os capitais devam fluir, em termos líquidos, dos países desenvolvidos para os países em desenvolvimento, ou seja, o padrão observado dos fluxos de capitais não é um puzzle. 


\section{Referências bibliográficas}

ACEMOGLU, D. Introduction to modern economic growth. New Jersey: Princeton University Press, 2009.

; JOHNSON, S. Unbundling institutions. Journal of Political Economy, v. 113, n. 5, p. 949-995, 2005.

; JOHNSON, S.; ROBINSON, J. A. The colonial origins of comparative development: an empirical investigation. American Economic Review, v. 91, n. 5, p. 13691401, 2001.

ALFARO, L.; KALEMI-OZCAN, S.; VOLOSOVYCH, V. Why doesn't capital flow from rich to poor countries? An empirical investigation. Review of Economics and Statistics, v. 90, n. 2, p. 347-368, 2008.

BALTAGI, B. H. Econometric analysis of panel data. 5. ed. Chichester: John Wiley \& Sons Ltd, 2008.

BARRO, R. J.; LEE, J. W. International data on educational attainment: update and implications. Oxford Economic Papers, v. 53, n. 3, p. 541-563, 2001.

BAUM, C. F. An introduction to modern econometrics using stata. Texas: Stata Press, 2006.

; SCHAFFER, M. E.; STILLMAN, S. Enhanced routines for instrumental variables/generalized method of moments estimation and testing. Stata Journal, v. 7, n. 4, p. $465-506,2007$.

Stata Journal, v. 3, n. 1, p. 1-31, 2003.

BEKAERT, G.; HARVEY, C. R.; LUNDBLAD, C. Does financial liberalization spur growth? Journal of Financial Economics, v. 77, n. 1, p. 3-55, 2005.

BIANCARELI, A. M. International liquidity cycles to developing countries in the financial globalization era. In: REUNIÓN DE ECONOMÍA MUNDIAL, 11, Huelva (España), 2009.

BIBOW, J. The international monetary (non-) order and the "global capital flows paradox”. The Levy Economics Institute, 2008. (Working Paper, n. 531).

CAMERON, A. C.; TRIVEDI, P. K. Microeconometrics using stata. Texas: Stata Press, 2009.

; - Microeconometrics: methods and applications. Cambridge: Cambridge University Press, 2005.

CARKOVIC, M.; LEVINE, R. Does foreign direct investment accelerate economic growth? In: MORAN, T. H.; GRAHAM, E. M.; BLOMSTROM, M. Does foreign direct investment promote development? Washington: Institute for International Economics, 2005.

CARNEIRO, R. Globalização e inconversibilidade monetária. Revista de Economia Política, v. 28, n. 4, p. 539-556, 2008. 
CARNEIRO, R. Globalização financeira e inserção periférica. Economia e Sociedade, v. 8, n. 2, p. 58-92, 1999.

CARVAlHO, F. J. C.; SICSÚ, J. Controvérsias recentes sobre controles de capitais. Revista de Economia Politica, v. 24, n. 2 (94), p. 163-184, 2004.

CASELLI, F.; FEYRER, J. The marginal product of capital. Quarterly Journal of Economics, v. 122, n. 2, p. 535-568, 2007.

CHINN, M.; ITO, H. A New measure of financial openness. Journal of Comparative Policy Analysis, v. 10, n. 3, p. 309-322, 2008.

CHIRINKO, R. S.; MALLICK, D. The marginal product of capital: a persistent international puzzle. CESIFO, 2008. (Working Paper, n. 2399).

CLEMENS, M. A.; WILLIAMSON, J. Wealth bias in the first global capital market boom. Economic Journal, v. 114, n. 2, p. 304-337, 2004.

COHEN, A. J.; HARCOURT, G. C. Capital theory controversy: scarcity, production, equilibrium and time. In: BLISS, C.; COHEN, A. J.; HARCOURT, G. C. (Org.), Capital theory. Massachusetts: Edward Elgar Publishing, 2005. v. I.

; HARCOURT, G. C. Whatever happened to the Cambridge capital theory controversies? Journal of Economic Perspectives, v. 17, n. 1, p. 199-214, 2003.

DAVIDSON, P. John Maynard Keynes. São Paulo: Actual Editora, 2011.

Keynes, post Keynesian analysis, and the open economies of the twenty-first century. In: ARESTIS, P.; McCOMBIE, J.; VICKERMAN, R. (Org.). Growth and economic development: essays in honour of A. P. Thirlwall. Cheltenham: Edward Elgar Publishing, 2006.

2002.

Financial markets, money and the real world. Massachusetts: Edward Elgar,

Is a plumber or a new financial architect needed to end global international liquidity problems? World Development, v. 28, n. 6, p. 1117-1131, 2000.

. Are grains of sand in the wheels of international finance sufficient to do the job when boulders are often required? The Economic Journal, v. 107, n. 442, p. 671-686, 1997.

EDISON, H. J.; LEVINE, R.; RICCI, A. L.; SLØK, T. International financial integration and economic growth. Journal of International Money and Finance, v. 21, n. 6, p. 749$776,2002$.

EICHENGREEN, B.; MUSSA, M.; DELL'ARICCIA, G.; DETRAGIACHE, E.; MILESIFERRETTI, G. M.; TWEEDIE, A. Capital account liberalization: theoretical and practical aspects. Washington: International Monetary Fund, 1998. (IMF, Occasional Paper, n. 172).

The cautious case for capital flows. Berkeley: University of California, 2007.

FAMA, E. Efficient capital markets II. Journal of Finance, v. 46, n. 5, p. 1575-1617, 1991. 
FAMA, E. Efficient capital markets: a review of theory and empirical work. Journal of Finance, v. 25, n. 2, p. 383-417, 1970.

GERTLER, M.; ROGOFF, K. North-south lending and endogenous domestic capital market inefficiencies. Journal of Monetary Economics, v. 26, n. 2, p. 245-266, 1990.

GLAESER, E. L.; LA-PORTA, R.; LOPEZ-DE-SILANES, F.; SHLEIFER, A. Do institutions cause growth? Journal of Economic Growth, v. 9, n. 3, p. 271-303, 2004.

HALL, R. E.; JONES, C. I. Why do some countries produce so much more output per worker than others? Quarterly Journal of Economics, v. 114, n. 1, p. 83-116, 1999.

HARCOURT, G. C. Some Cambridge controversies in the theory of capital. Cambridge: Cambridge University Press, 1972.

HENRY, P. B. Capital account liberalization: theory, evidence, and speculation. Journal of Economic Literature, v. 45, n.4, p. 887-935, 2007a.

Comments and discussion on PRASAD, E.; RAJAN, R.; SUBRAMANIAN, A. Foreign capital and economic growth. Brookings Papers on Economic Activity, v. 38, n. 1, p. 153-230, 2007b.

INTERNATIONAL MONETARY FUND. World economic outlook database. Washington: IMF, 2009. . International financial statistics. Washington: IMF, 2008.

KEYNES, J. M. The general theory of employment. The Quarterly Journal of Economics, v. 51, n. 2, p. 209-223, 1937.

. The general theory of employment, interest and money. New York: Harcourt Brace Company, 1936.

KRAAY, A. In search of the macroeconomic effects of capital account liberalization. World Bank, 1998.

KREGEL, J. A. Financial liberalization and domestic policy space: theory and practice with reference to Latin America. In: ARESTIS, P.; PAULA, L. F. R. (Org.). Financial liberalization and economic performance in emerging countries. Hampshire: Palgrave Macmillan, 2008.

Prefácio. In: SICSÚ, J.; FERRARI FILHO, F. (Org.). Câmbio e controles de capitais: avaliando a eficiência de modelos macroeconômicos. Rio de Janeiro: Elsevier, 2006.

LANE, P.; MILESI-FERRETTI, J. M. The external wealth of nations mark II: revised and extended estimates for foreign assets and liabilities. Journal of International Economics, v. 73 , n. 2, p. 223-250, 2007.

; . The external wealth of nations: measures of foreign assets and liabilities for industrial and developing countries. Journal of International Economics, v. 55 , n. 2, p. 263-294, 2001. 
LA PORTA, R.; LOPEZ-DE-SILANES, F.; SHLEIFER, A. The economic consequences of legal origins. Journal of Economic Literature, v. 46, n. 2, p. 285-332, 2008.

; _ ; _ _ VISHNY, R. The quality of government. Journal of Law, Economics \& Organization, v. 15, n. 1, p. 222-279, 1999.

LAZZARINI, A. Revisiting the Cambridge capital theory controversies: a historical and analytical study. Pavia: Pavia University Press, 2011.

LUCAS, R. Why doesn't capital flow from rich to poor countries? American Economic Review, v. 80, n. 2, p. 92-96, 1990.

OBSTFELD, M; TAYLOR, A. M. Global capital markets: integration, crisis, and growth. Cambridge: Cambridge University Press, 2004.

; ROGOFF, K. Foundations of international macroeconomics. Cambridge, Massachusetts: The MIT Press, 1996.

OCAMPO, J. A. International asymmetries and the design of the international financial system. Santiago: Cepal, 2001. (Series Temas de Coyuntura, n. 15).

POLITICAL SERVICE RISK GROUP. International Country Risk Guide. PSRG, New York, 2008.

PRASAD, E.; RAJAN, R.; SUBRAMANIAN, A. Foreign capital and economic growth. Brookings Papers on Economic Activity, v. 38, n. 1, p. 153-230, 2007.

PRATES, D. M. As assimetrias do sistema monetário e financeiro internacional. Revista de Economia Contemporânea, v. 9, n. 2, p. 263-288, 2005.

Crises financeiras dos paises "emergentes": uma interpretação heterodoxa. Tese (Doutoramento)-Instituto de Economia. Universidade Estadual de Campinas, Campinas, 2002.

QUINN, D. P. The correlates of change in international financial regulation. American Political Science Review, v. 91, n. 3, p. 531-551, 1997.

REINHART, C.; ROGOFF, K. Serial default and the "paradox" of rich to poor capital flows. American Economic Review, v. 94, n. 2, p. 52-58, 2004.

ROBINSON, J. The production function and the theory of capital. Review of Economic Studies, v. 21, n. 2, p. 81-106, 1953-1954.

RODRIK, D. Who needs capital-account convertitility? In: PETER, B. K. (Org.). Should the IMF pursue capital-account convertitility? Princeton University, Department of Economics, 1998. (Essays in International Finance, n. 207).

; SUBRAMANIAN, A. Why did financial globalization disappoint? IMF Staff Papers, v. 56, n. 1, p. 112-138, 2009.

SAMUELSON, P. A. Parable and Realism in capital theory: the surrogate production function. Review of Economic Studies, v. 29, n. 3, p. 193-206, 1962. 
SAMUELSON, P. A summing up. Quarterly Journal of Economics, v. 80, n. 4, p. 568$583,1966$.

SCHULARICK, M. A tale of two 'globalizations': capital flows from rich to poor in two eras of global finance. International Journal of Finance and Economics, v. 11, n. 4, p. 339$354,2006$.

SERRANO, F. Do ouro imóvel ao dólar flexível. Economia e Sociedade, v. 11, n. 2, p. $237-$ 253, 2002.

STOCK, J. H.; YOGO, M. Testing for weak instruments in linear IV regression. In: ANDREWS, D. W.; STOCK, J. H. (Org.). Identification and inference for econometric models: essays in honor of Thomas Rothenberg. Cambridge: Cambridge University Press, 2005.

STULZ, R. M. The limits of financial globalization. Journal of Finance, v. 60, n. 4, p. $1595-1638,2005$.

TAVARES, M. C.; MELIN, L. E. Pós-escrito 1997: A reafirmação da hegemonia norteamericana. In: TAVARES, M. C.; FIORI, J. L. (Org.). Poder e dinheiro: uma economia política da globalização. Petrópolis: Editora Vozes, 1997.

WOOLDRIDGE, J. M. Econometric analysis of cross section and panel data. 2. ed. Cambridge, MA: The MIT Press, 2010.

WHITE, H. A heteroskedasticity-consistent covariance matrix estimator and a direct test for heteroskedasticity. Econometrica, v. 48, n. 4, p. 817-838, 1980.

WORLD BANK. World Development Indicators. Washington: World Bank, 2007. 
Padrão dos fluxos de capitais: teoria, evidência e puzzle

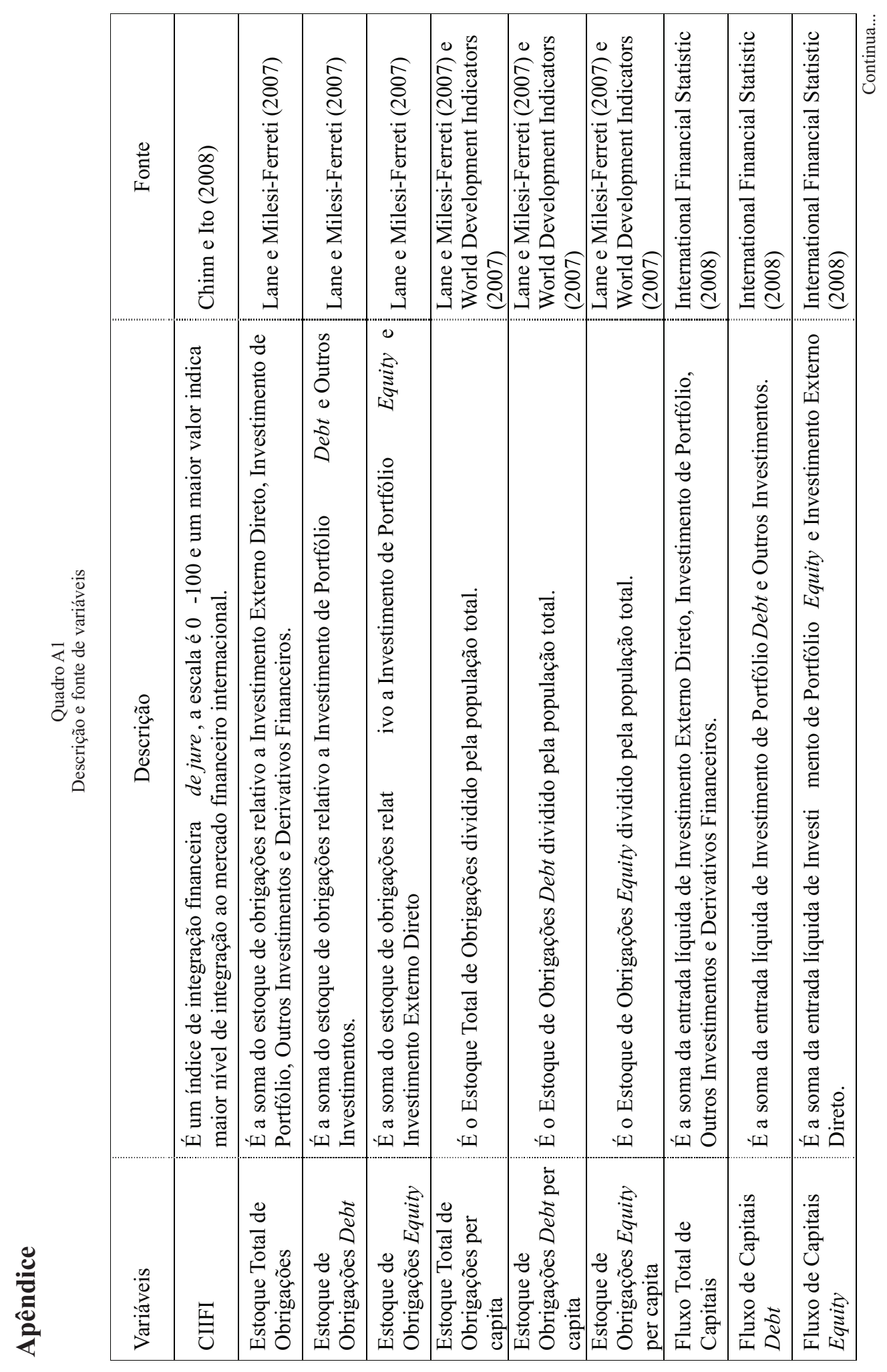

Economia e Sociedade, Campinas, v. 23, n. 1 (50), p. 63-105, abr. 2014. 


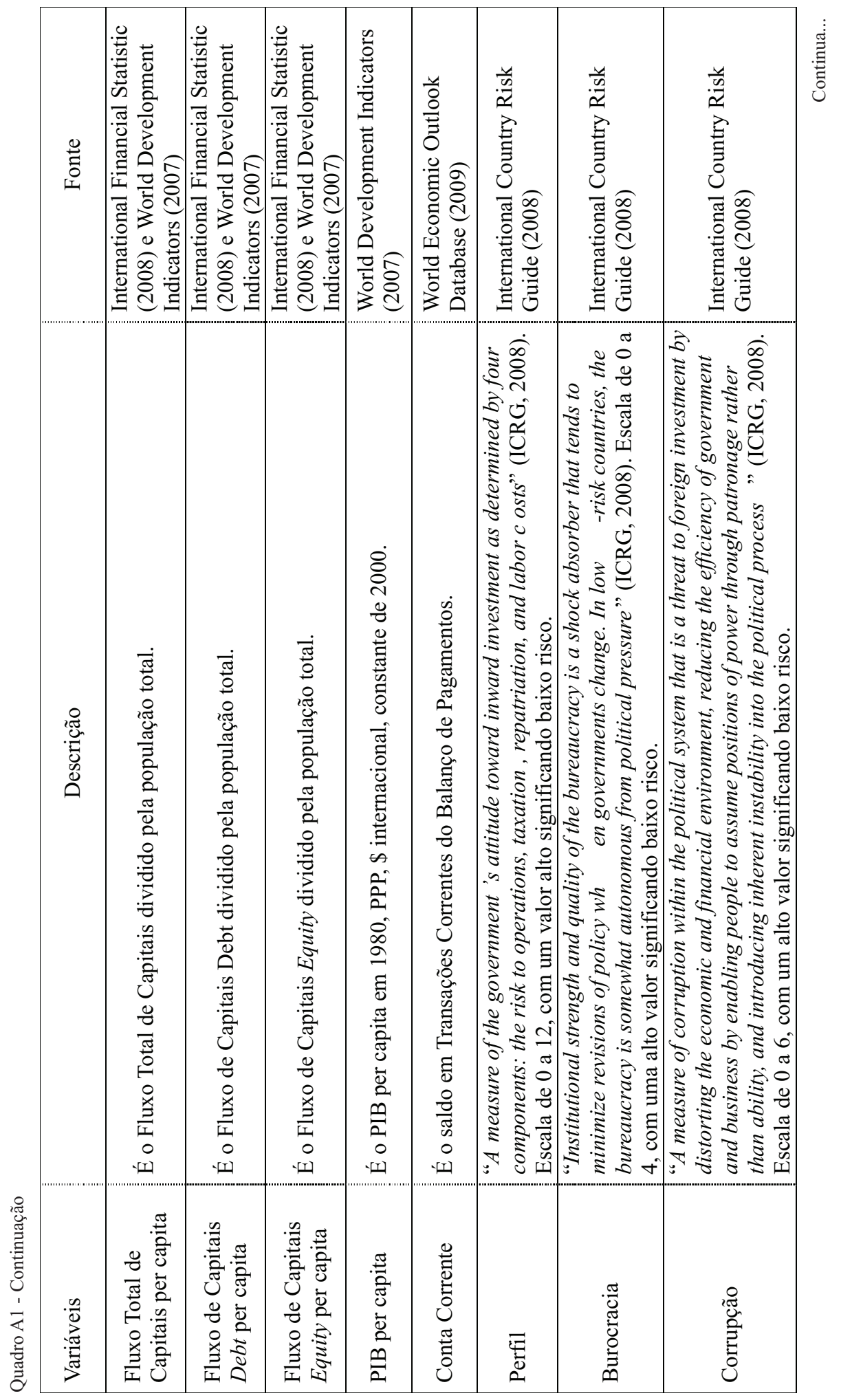


Padrão dos fluxos de capitais: teoria, evidência e puzzle

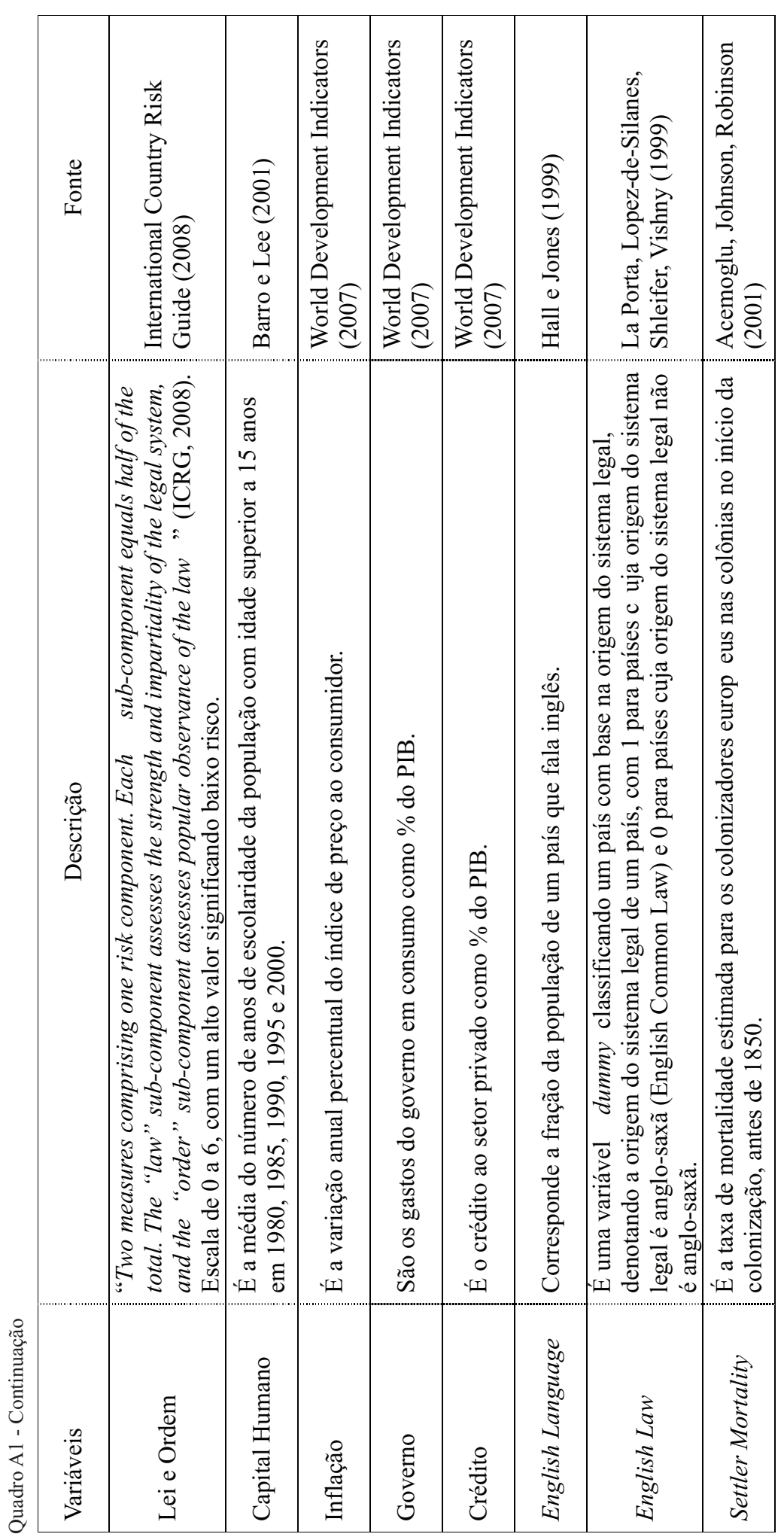

Economia e Sociedade, Campinas, v. 23, n. 1 (50), p. 63-105, abr. 2014. 
Quadro A2

Definições de amostras

A amostra utilizada para as análises nas seções 2 e 3 é composta de 105 países, 22 países desenvolvidos e 83 países em desenvolvimento. Países desenvolvidos: Austrália, Áustria, Bélgica, Canadá, Dinamarca, Finlândia, França, Alemanha, Grécia, Islândia, Irlanda, Itália, Japão, Holanda, Nova Zelândia, Noruega, Portugal, Espanha, Suécia, Suíça, Reino Unido, Estados Unidos. Países emergentes: Argentina, Brasil, Chile, China, Colômbia, Egito, Hong Kong, Índia, Indonésia, Israel, Jordânia, Coreia, Malásia, México, Paquistão, Peru, Filipinas, Arábia Saudita, Singapura, África do Sul, Tailândia, Turquia, Venezuela. Demais Países em Desenvolvimento: Argélia, Bahrein, Bangladesh, Benin, Bolívia, Botsuana, Burkina Faso, Camarões, Chade, República. Democrática. do Congo, República. do Congo, Costa Rica, Costa do Marfim, República Dominicana, Equador, El Salvador, Etiópia, Fiji, Gabão, Gana, Guatemala, Guiné, Haiti, Honduras, Irã, Jamaica, Quênia, Kuwait, Líbano, Líbia, Madagáscar, Malawi, Mali, Malta, Maurício, Marrocos, Birmânia, Nepal, Nicarágua, Níger, Nigéria, Omã, Panamá, Papua Nova Guiné, Paraguai, Catar, Ruanda, Senegal, Sri Lanka, Sudão, Suazilândia, Síria, República Árabe, Tanzânia, Togo, Trindade e Tobago, Tunísia, Uganda, Emirados Árabes Unidos, Uruguai e Zâmbia. Observação: A amostra utilizada para a análise do Fluxo Total de Capitais, Fluxo de Capitais Equity e Fluxo de Capitais Debt não contém dados para os países República. Democrática do Congo, Catar e Emirados Árabes Unidos.

A amostra utilizada para a estimação das equações apresentadas nas colunas 1.1, 2.1, e 3.1 das Tabelas A1 e A2 é formada pela amostra de 105 países utilizada nas análises das seções 2 e 3 . Observações: i) a amostra utilizada para a estimação da equação 1.1 da Tabela A1 exclui - República. Democrática do Congo, República do Congo, Etiópia, Gabão, Guiné, Irã, Líbano, Líbia, Birmânia, Nicarágua, Nigéria, Panamá, Catar, Tanzânia, Uganda, Emirados Árabes Unidos; ii) a amostra utilizada para a estimação da equação 2.1 da Tabela A1 exclui República Democrática do Congo, Etiópia, Gabão, Guiné, Líbano, Líbia, Birmânia, Catar, Tanzânia, Uganda, Emirados Árabes Unidos; iii) a amostra utilizada para a estimação da equação 3.1 da Tabela A1 exclui Brasil, Egito, Hong Kong, Benin, República Democrática do Congo, República. do Congo, Costa Rica, Costa do Marfim, Equador, Etiópia, Gabão, Guiné, Irã, Líbano, Líbia, Madagáscar, Birmânia, Nicarágua, Nigéria, Panamá, Papua Nova Guiné, Paraguai, Catar, Tanzânia, Trindade e Tobago, Uganda, Emirados Árabes Unidos; iv) a amostra utilizada para a estimação da equação 1.1 da Tabela A2 exclui Etiópia, Guiné, Líbano, Líbia, Birmânia, Catar, Tanzânia, Uganda; v) a amostra utilizada para a estimação da equação 2.1 da Tabela A2 exclui. República Democrática do Congo, Etiópia, Guiné, Líbano, Líbia, Birmânia, Catar, Tanzânia, Uganda; vi) a amostra utilizada para a estimação da equação 3.1 da Tabela A2 exclui Etiópia, Guiné, Líbano, Líbia, Birmânia, Catar, Tanzânia e Uganda.

A amostra utilizada para a estimação das equações (1.2-1.5, 2.2-2.5, 3.2-3.5) apresentadas nas Tabelas A1, A2, A1.1 e A2.1 é formada por 79 países, 22 países desenvolvidos e 57 países em desenvolvimento, selecionada dentre a amostra de 105 países utilizada para a análise nas seções 1 e 2 com base na disponibilidade de dados para as variáveis utilizadas na análise de regressão. Países desenvolvidos: Austrália, Áustria, Bélgica, Canadá, Dinamarca, Finlândia, França, Alemanha, Grécia, Islândia, Irlanda, Itália, Japão, Holanda, Nova Zelândia, Noruega, Portugal, Espanha, Suécia, Suíça, Reino Unido, Estados Unidos. Países emergentes: Argentina, Brasil, Chile, China, Colômbia, Egito, Hong Kong, Índia, Indonésia, Israel, Jordânia, Coreia, Malásia, México, Paquistão, Peru, Filipinas, Singapura, África do Sul, Tailândia, Turquia, Venezuela. Demais Países em Desenvolvimento: Argélia, Bahrein, Bangladesh, Bolívia, Botsuana, Camarões, República do Congo, Costa Rica, República Dominicana, Equador, El Salvador, Gana, Guatemala, Haiti, Honduras, Irã, Jamaica, Quênia, Kuwait, Malawi, Mali, Nicarágua, Níger, Panamá, Papua Nova Guiné, Paraguai, Senegal, Sri Lanka, Sudão, Síria, República Árabe, Togo, Trindade e Tobago, Tunísia, Uruguai e Zâmbia. Observações: i) para as equações estimadas nas colunas 1.2-1.5 das Tabelas A1 e A1.1, os países República do Congo, Irã, Nicarágua e Panamá não constam na amostra; ii) para as equações estimadas nas colunas 3.2-3.5 das Tabelas A1 e A1.1, Brasil, Egito, Hong Kong, República do Congo, Costa Rica, Equador, Irã, Nicarágua, Panamá, Papua Nova Guiné e Trinidade e Tobago não constam na amostra; iii) em adição, para todas as equações estimadas incluindo Burocracia como variável explanatória nas colunas 1.4, 2.4 e 3.4 das Tabelas A1, A1.1, A2 e A2.1, Haiti e Mali não constam na amostra.

Continua... 
Quadro A2 - Continuação

A amostra utilizada para a estimação das equações apresentadas nas Tabelas A1.2 e A2.2 é formada por 46 países, 4 países desenvolvidos e 42 países em desenvolvimento, selecionada dentre a amostra de 105 países utilizada para a análise nas seções 1 e 2, com base na disponibilidade de dados para as variáveis utilizadas na análise de regressão. Países desenvolvidos: Austrália, Canadá, Nova Zelândia, Estados Unidos. Países emergentes: Argentina, Brasil, Chile, Colômbia, Egito, Hong Kong, Índia, Indonésia, Malásia, México, Paquistão, Peru, Singapura, África do Sul, Venezuela. Demais Países em Desenvolvimento: Argélia, Bangladesh, Bolívia, Camarões, República do Congo, Costa Rica, República Dominicana, Equador, El Salvador, Gana, Guatemala, Haiti, Honduras, Jamaica, Quênia, Mali, Nicarágua, Níger, Panamá, Paraguai, Senegal, Sri Lanka, Sudão, Togo, Trindade e Tobago, Tunísia e Uruguai. Observações: i) para as equações estimadas nas colunas 1.2-1.5 da Tabela A1.2, os países República do Congo, Nicarágua e Panamá não constam na amostra; ii) para as equações estimadas nas colunas 3.2-3.5 da Tabela A1.2, os países Brasil, Egito, Hong Kong, República do Congo, Costa Rica, Equador, Nicarágua, Panamá e Trindade e Tobago não constam na amostra; iii) em adição, para todas as equações estimadas, incluindo Burocracia como variável explanatória, nas colunas 1.4, 2.4 e 3.4 das Tabelas A1.2 e A2.2, os países Haiti e Mali não constam na amostra.

A amostra utilizada para a estimação das equações apresentadas nas Tabelas A3 e A4 é formada pela amostra de 105 países utilizada nas análises das seções 2 e 3. A dimensão temporal dos dados é 5 (1980-1984, 19851989, 1990-1994, 1995-1999, 2000-2004) e a dimensão cross-section é 105. O total de observações (NT) seria 525 , mas perdemos observações pois não temos todas as observações relativas a todas as variáveis para todos os países em todos os períodos, ou seja, o painel é desbalanceado. 


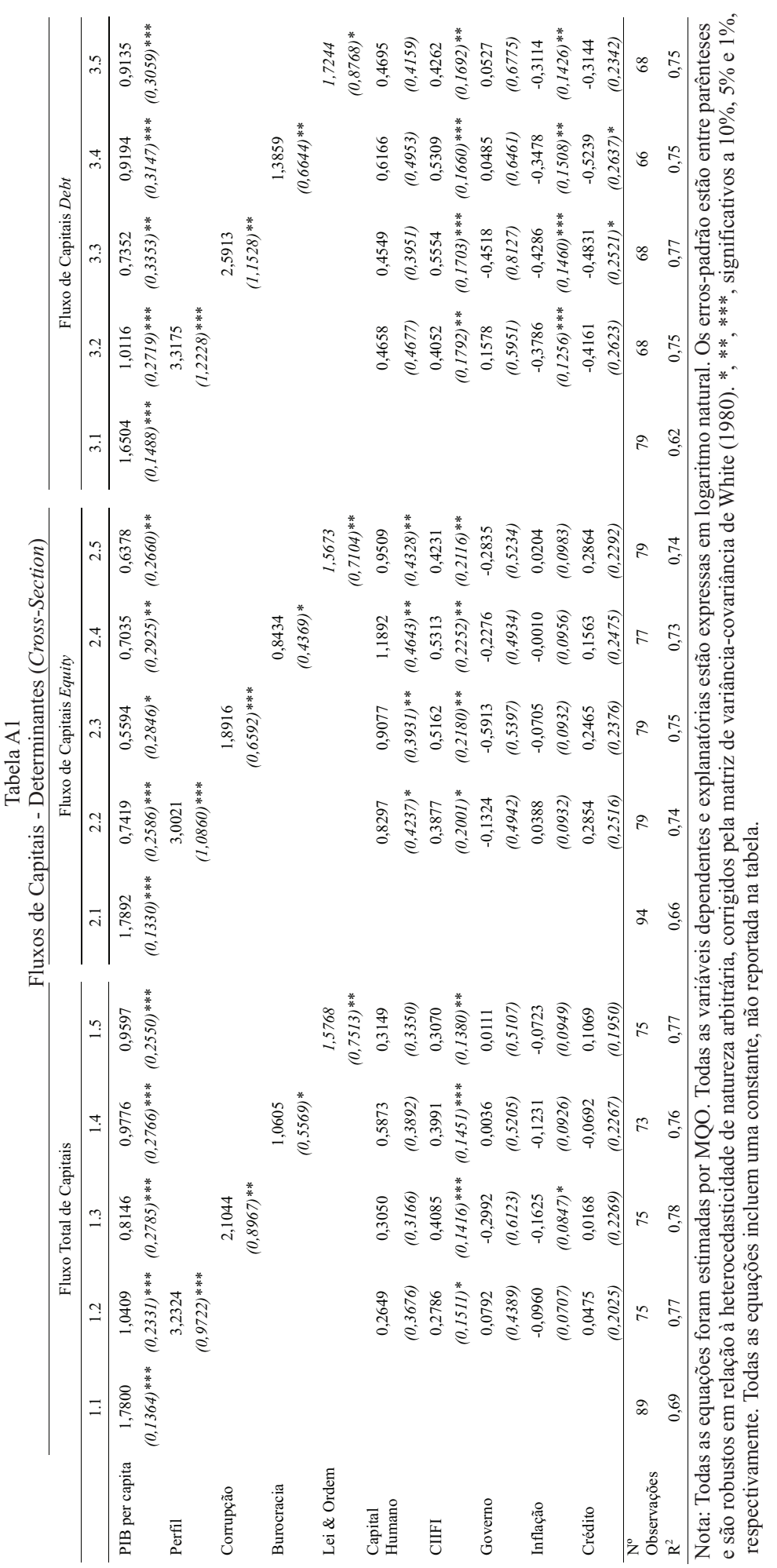




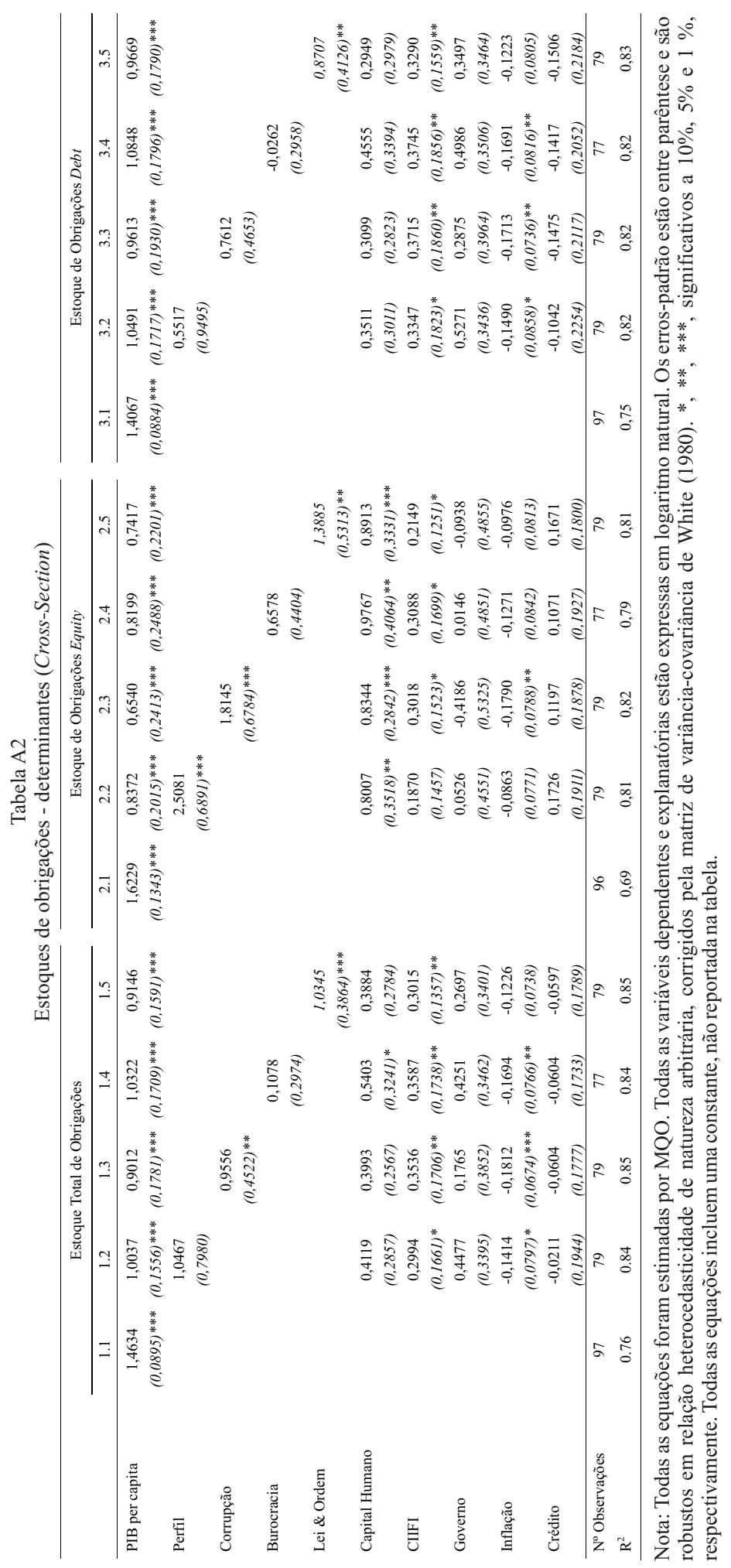



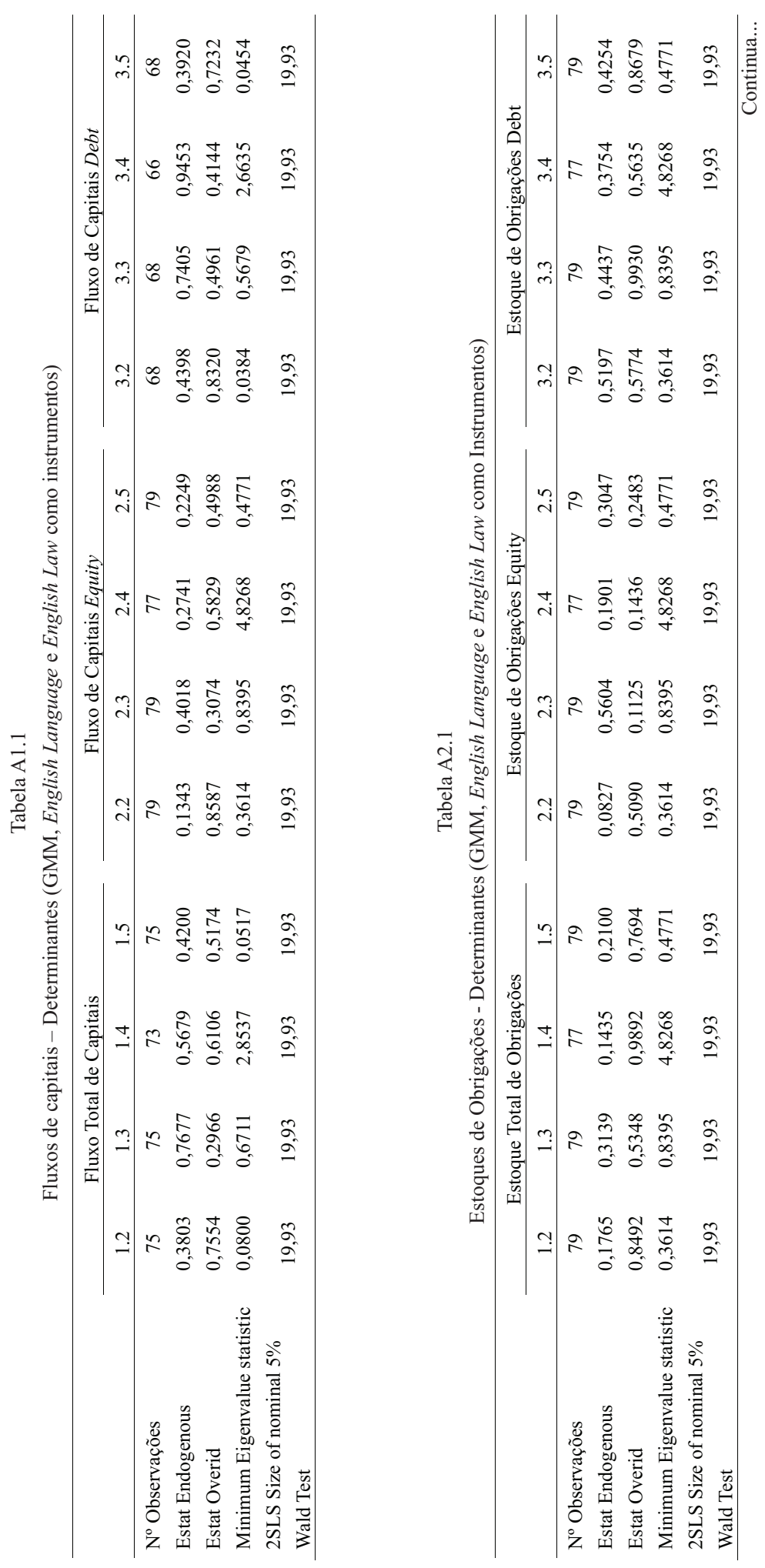

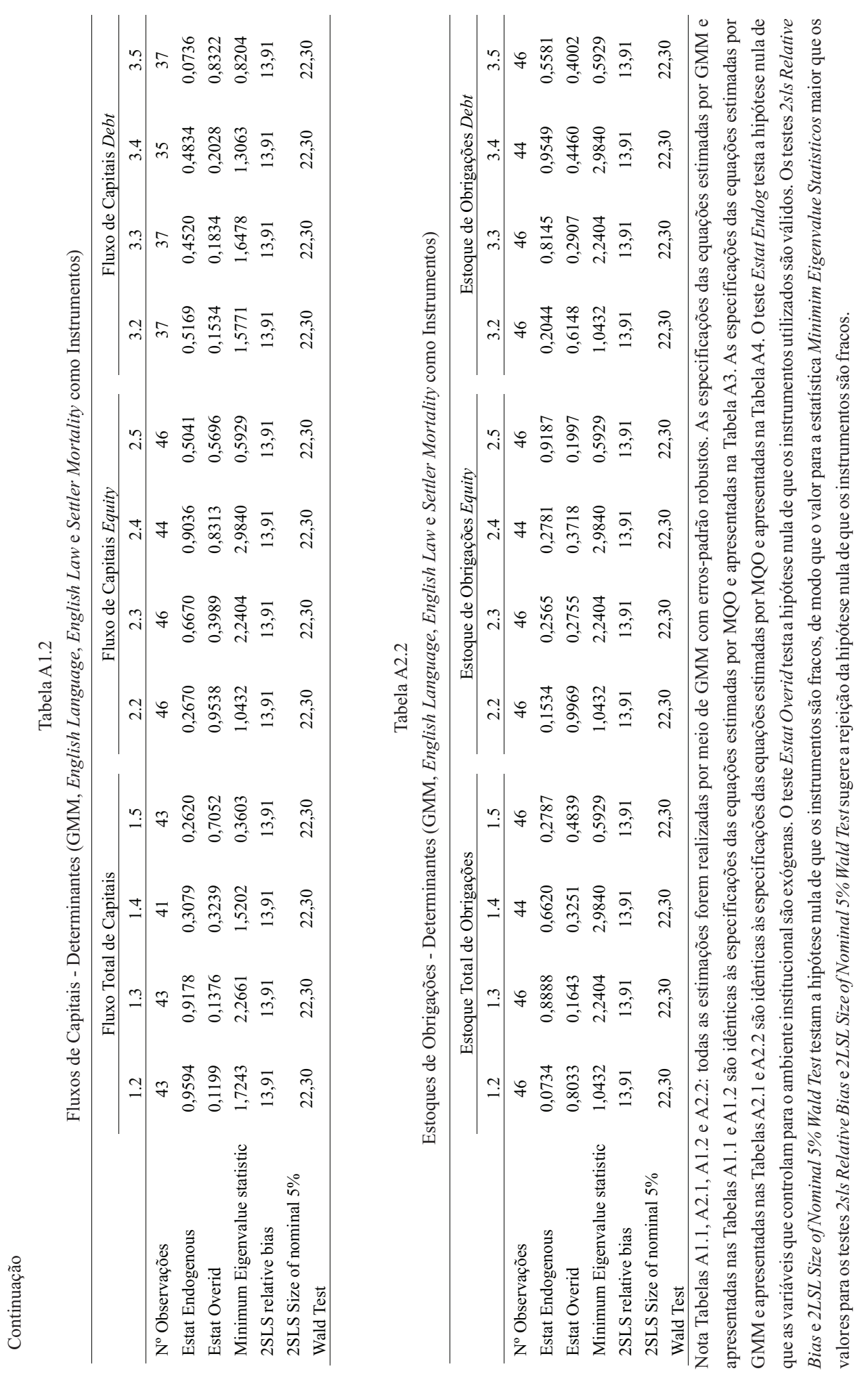

Economia e Sociedade, Campinas, v. 23, n. 1 (50), p. 63-105, abr. 2014. 
Aderbal Oliveira Damasceno

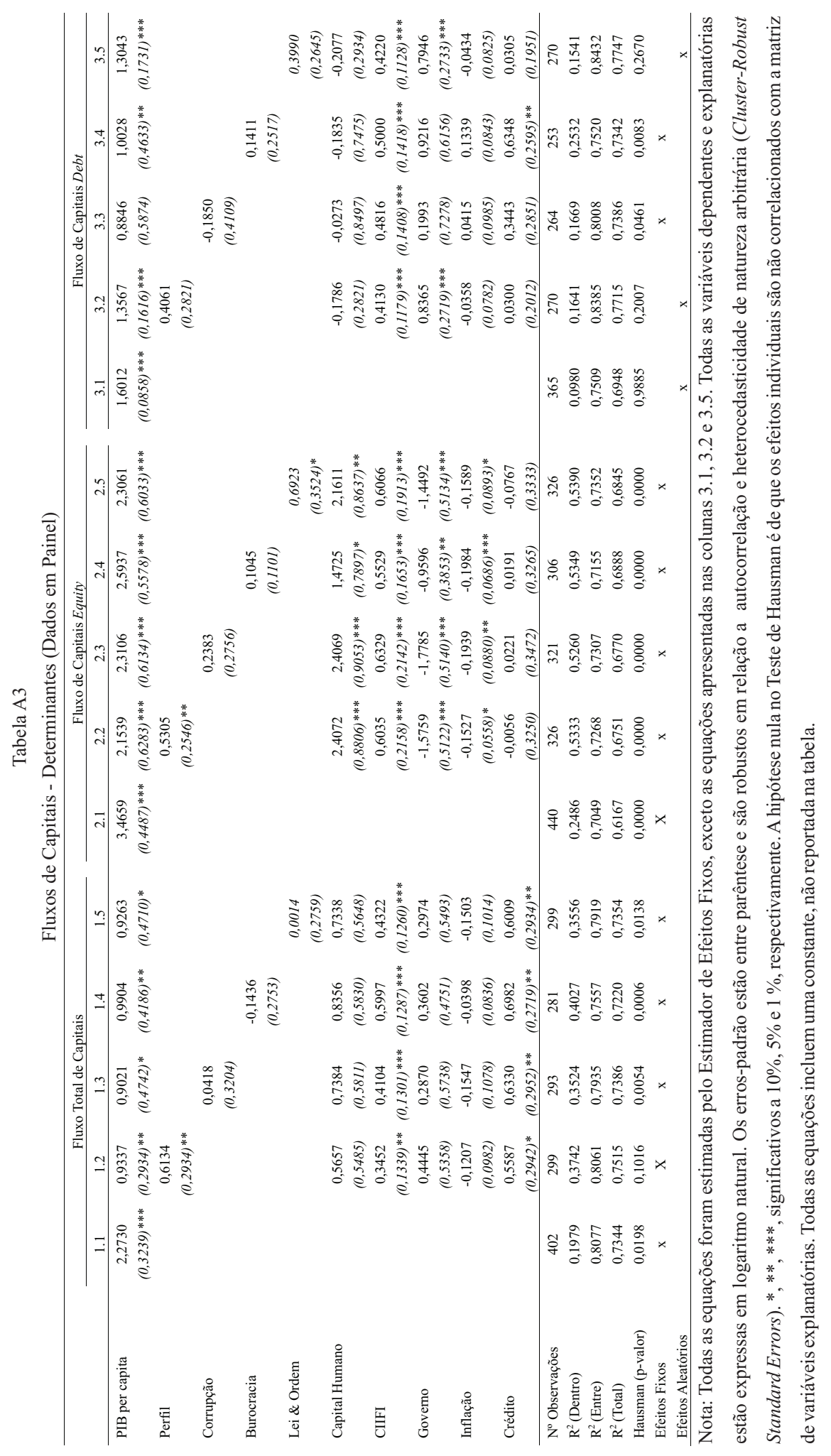


Padrão dos fluxos de capitais: teoria, evidência e puzzle

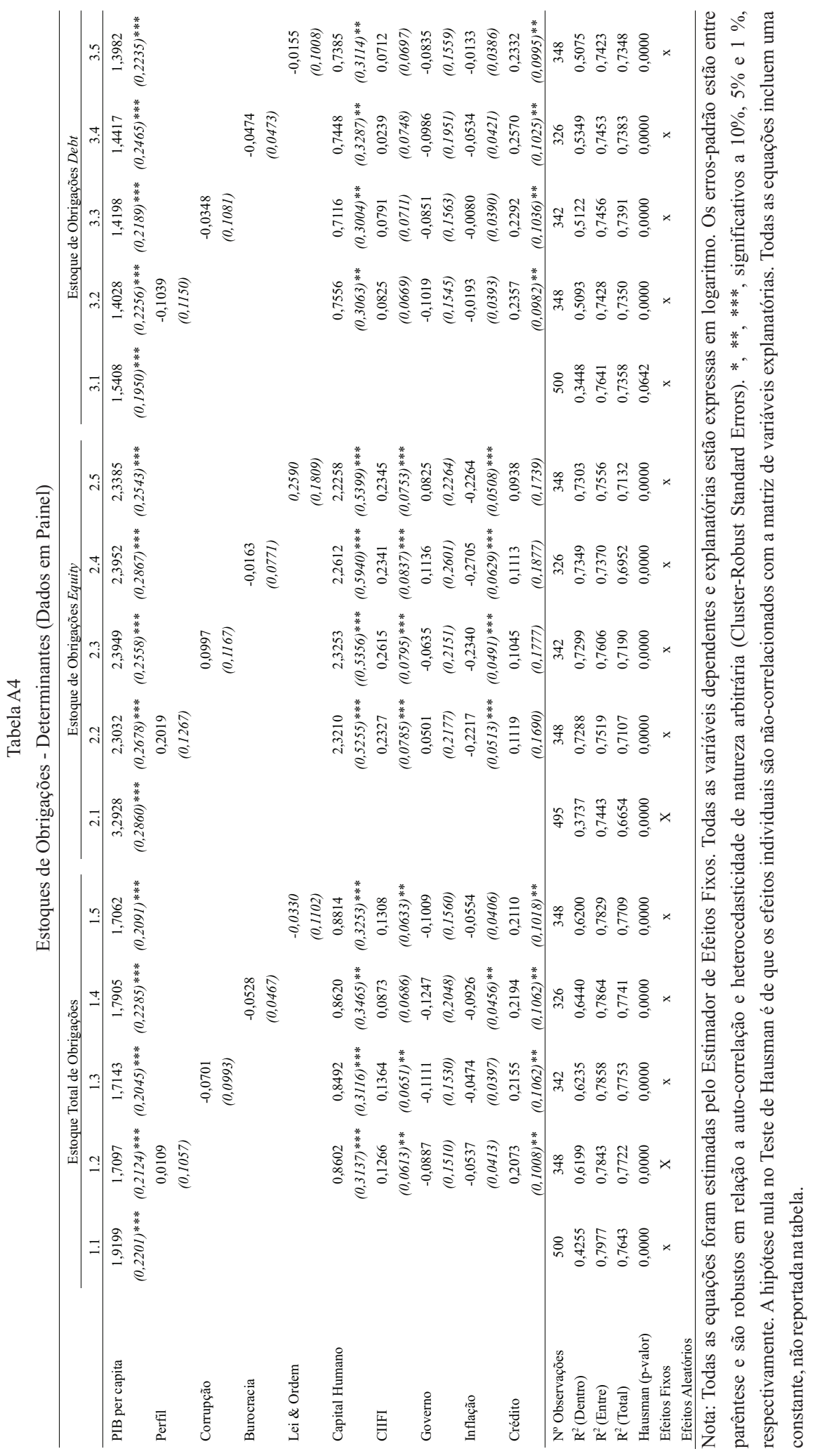

Economia e Sociedade, Campinas, v. 23, n. 1 (50), p. 63-105, abr. 2014. 